SUBCONTRACT NP-1

APPENDIX B

SUPPLEMENTAL AGREEMENT NO. 7

Effective October 1, 1967

SUBCONTRACT WORK STATEMENT

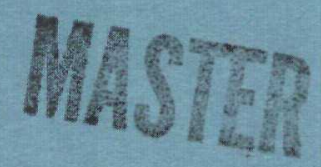

May 2, 1968

\title{
FILE CO?Y
}

NRO

Technical Document Center

WORK TO BE PERFORMED DURING THE PERIOD

OCTOBER 1, 1967 THROUGH SEPTEMBER 30, 1968 


\section{DISCLAIMER}

This report was prepared as an account of work sponsored by an agency of the United States Government. Neither the United States Government nor any agency Thereof, nor any of their employees, makes any warranty, express or implied, or assumes any legal liability or responsibility for the accuracy, completeness, or usefulness of any information, apparatus, product, or process disclosed, or represents that its use would not infringe privately owned rights. Reference herein to any specific commercial product, process, or service by trade name, trademark, manufacturer, or otherwise does not necessarily constitute or imply its endorsement, recommendation, or favoring by the United States Government or any agency thereof. The views and opinions of authors expressed herein do not necessarily state or reflect those of the United States Government or any agency thereof. 


\section{DISCLAIMER}

Portions of this document may be illegible in electronic image products. Images are produced from the best available original document. 
This report was prepared as an account of work sponsored by the United States Government. Neither the United States nor the United States Energy Research and Development Administration, nor any of their employees, nor any of their contractors, subcontractors, or their employees, makes any warranty, express or implied, or assumes any legal liability or responsibility for the accuracy, completeness or usefulness of any information, apparatus, product or process disclosed, or represents that its use would not infringe privately owned rights.

May 2, 1968

SUBCONTRACT NP-1

APPENDIX B

SUPPIEMENTAL AGREEMENIT NO. 7

Effective October 1, 1967

SUBCONTRACT WORK STATEMEINT

WORK TO BE PERFORMED DURING THE PERIOD

OCTOBER 1, 1967 THROUGH SEPTEMBER 30, 1968 


\section{SUBCONTRACT NP-1}

APPEINIX B

STATEMEENT OF WORK

Based on the KIWI and the PHOEBUS technology developed by the Los Alamos Scientific Laboratory, and on technology and designs developed in the NERVA Program, the subcontractor shall utilize its best efforts to conduct the following scope of research and development work for the period October 1 , 1967, through september 30, 1968. This work supplements the work performed in previous periods from July 10, 1961, through September 30, 1967.

The subcontractor shall comply with the following documents in conducting the work under this subcontract:

1. Structural Design Specification, SNPO-C-1, December, 1965, as mudified by AGC/WANL/SINPO-C Agreements.

2. NASA Publication, NPC 200-2, April, 1962, as interpreted by WANL-TNR088, Rev. F.

3. NASA Publication, NPC 250-1, July, 1963, in accordance with Section II of WANL-TNR-088, Rev. F.

4. NASA Publication, NPC 200-4, Rev. A, as interpreted by the WANL Quality Workmanship Standard, WANL-QWS-I. 
Subtask 1.1 - Englne System

Project 1100 - Engine Test Support - Technology

A. Engineering

(1) Coordinate nuclear subsystem Input to the XE-2 Test Specification and perticipate in review and approvel of the Test Specification.

(2) Coordinate and prepare proposed modifications to the XE-I and XE-2 Test Specifications. Review and coordinate WANL comments and concurrence action for proposed modifications to the XECF, $\mathrm{XE}-1$, and $\mathrm{XE}-2$ Test Specifications.

(3) Coordinate and document changes to the nuclear subsystem measurements requirements for XECF, XE-1, and XE-2. Review and coordinate comments and concurrence action for proposed changes to the XECF, $\mathrm{XE}-1$, and $\mathrm{XE}-2$ Measurements Requirements Lists (MRI).

(4) Review and coordinate comments and concurrence action on NTO procedures for the assembly, operation, disassembly, and postoperative examination for XECF, XE-1, and XE-2.

(5) Contribute to the SPEAR Team efforts for XECF and XE- 1 .

(6) Coordinate and prepare nuclear subsystem input to the XE-I FinaI Reports.

(7) Develop requirements, and coordinate nuclear subsystem requirements, for XE-2 ETS-1 facility checkout tests. Provide necessary engineering support for ETS-I facility checkout tests and evaluate data.

(8) Analyze test data, develop analysis requirements, including requirements for WANL and AGC computer studies, perform analyses and provide technical support to other WANL engineering groups for $\mathrm{XE}-1$ and $\mathrm{XE}-2$, to provide the following:

a. Preliminary studies needed to define test details

b. Facility requirements

c. Cooldown sequences

d. Final verification of test profiles

e. Assistance in the preparation of safeguards reports.

(9) Provide technical support to AGC in the planning and execution of the $X E-1$ and $X E-2$ tests, including pre-test readiness reviews.

B. Fabrication - Not applicable.

C. Testing - Not applicable.

D. Tooling - Not applicable. 
Subtask 1.1 - Engine System

Project 1102 - Engine Test Support - Engine

A. Engineering

(1) Prepare the E-I Reactor Internal Measurements (RIM) list.

(2) Participate in and provide technical support to AGC, in the planning of the NERVA engine test series.

(3) Support the preparation of the AFSCM 310 Data Items specified in Project 1112 and the INEVA Engine CEI Specification - Part 1, as appropriate.

B. Fabrication - Not applicable

C. Testing - Not applicable

D. Tooling - Not applicable 
Subtask 1.1 - Englne System

Project 1712 - Engine Configuration Documentation - Engine

A. Engineering

(1) Coordinate, prepare and maintain the Nuclear Subsystem-Contract End Item Specification - Part I in accordance with the management and engineering principles delineated in the AFSCM 375 series of documents and exhibits. This specification shall be in the format of, and include the technical content specified in the following AFSCM 310 Data Items:
a. $\quad C-2-46 \cdot 0-1$
CEI Specification - Part I
b. $5-52-6.1$
Functional Flow Diagrams
c. $5-53-6.1$
Requirements Allocation Sheets
d. $s-55-6.1$
Schematic Block Diagrams
e. $s-56-6.0$
Time Iine Sheets

(2) Coordinate, prepare and maintain the following documents in accordance with the management and engineering principles delineated in the AFSCM 375 series of documents and exhibits for the Nuclear Subsystem - Contract End Item. These documents shall be in the format of, and include the technical content of, the following AFSCM 310 Data Items:
a. $C-29-40.1$
System Allocation Document
b. E-105
Engineering Data (Category A) for Design Evaluation
c. $\mathrm{E}-106$
Engineering Data (Category B) Interface Control
d. $s-38-21.0$
Preliminary Environmental Vibration and Noise Report
e. T-102
Category I Test Plan/Procedures
f. $C-26-64.0$
System Modification Design Data and Reports
g. $\quad \mathrm{L}-2-17 \cdot 0-2$
Packaging, Handling and Transportability Plan
h. $5-47-43.1$
Weight and Balance Status Report
i. $s-54-6.1$
Trade Study Reports
j. T-119
Test Reports - Development and Qualification 
Project 1112 (Cont.)

$\begin{array}{ll}\text { k. } & \mathrm{T}-134 \\ \text { 1. } & \mathrm{S}-58-6.1 \\ \text { m. } & \mathrm{T}-101 \\ \text { n. } & \mathrm{S}-21 \\ \text { o. } & \mathrm{S}-65\end{array}$

Test Facility Requirements Documents

Facility Interface Sheets

System Test Plan

Contamination Control Plan

Corrosion Prevention and Control Plan

(3) Issue one (1) month prior to conduct of the Nuclear Subsystem Contract End Item - Preliminary Design Review, as a minimum, the following:

$$
\begin{aligned}
& \text { a. Data Items }(\mathrm{C}-2-46.0-1)(\mathrm{S}-52-6.1)(\mathrm{S}-53-6.1)(\mathrm{S}-55-6.1) \\
& \text { and }(\mathrm{S}-56-6.0) \\
& \text { D. Data Items }(\mathrm{E}-105)(\mathrm{E}-106)(\mathrm{T}-102)(\mathrm{I}-2-17.0-2)(\mathrm{T}-134) \\
& (\mathrm{S}-58-6.1)(\mathrm{T}-10 \mathrm{I})(\mathrm{S}-65) \text { and }(\mathrm{S}-2 \mathrm{I})
\end{aligned}
$$

(4) Coordinate, prepare and maintain the Control Drum Actuator System Contract End Item Specification - Part I in accordance with the management and engineering principles delineated in the AFSCM 375 series of documents and exhibits. This specification shall be in the format of, and include the technical content specified in the following AFSCM 310 Data Item:

$$
\text { a. C-2-46.0-1 CEI Specification - Part I }
$$

(5) Coordinate, prepare and maintain the following documents in accordance with the management and engineering principles delineated in the AFSCM 375 series of documents and exhibits for the Control Drum Actuator System - Contract End Item. These documents shall be in the format of, and include the technical content of the following AFSCM 310 Data Items:

$$
\begin{aligned}
& \text { a. }(\mathrm{E}-105)(\mathrm{E}-106)(\mathrm{T}-102)(\mathrm{C}-26-64.0)(\mathrm{L}-2-17.0-2)(\mathrm{T}-119) \\
& \text { and }(\mathrm{S}-21)
\end{aligned}
$$

(6) Issue one (1) month prior to conduct of the Control Drum Actuator System - Contract End Item - Preliminary Design Review, as a minimum, the following:

$$
\begin{aligned}
& \text { a. Data Item }(\mathrm{C}-2-46 \cdot 0-1) \\
& \text { b. Data Item }(\mathrm{E}-105)(\mathrm{E}-106)(\mathrm{T}-102)(\mathrm{L}-2-17.0-2) \text { and }(\mathrm{S}-21)
\end{aligned}
$$

(7) Coordinate, prepare and maintain the Structural Support Coolant Valve and Actuator System - Contract End Item Specification Part $I$ in accordance with the management and engineering principles delineated in the AFSCM 375 series of documents and exhibits. This specification shall be in the format of, and include the technical content specified in the following AFSCM 310 Data Item:

a. C-2-46.0-I CEI Specification - Part I 
Project 1172 (Cont.)

(8) Coordinate, prepare and maintain the following documents in accordance with the management and engineering principles delineated in the AFSCM 375 series of documents and exhibits for the structural Support Coolant Valve and Actuator System - Contract End Item. These documents shall be in the format of, and include the technical content of the following AFSCM 310 Data Items:

a. $(\mathrm{E}-105)(\mathrm{E}-106)(\mathrm{T}-102)(\mathrm{C}-26-64.0)(\mathrm{L}-2-17.0-2)(\mathrm{T}-119)$
and $(\mathrm{S}-2 \mathrm{I})$

(9) Issue one (1) month prior to conduct of the Structural Support Coolant Valve and Actuator System - Contract End Item - Preliminary Design Review, as a minimum, the following:

a. Data Item $(\mathrm{C}-2-46.0-1)$

b. Data Items $(\mathrm{E}-105)(\mathrm{E}-106)(\mathrm{T}-102)(\mathrm{L}-2-17.0-2)$ and $(\mathrm{S}-21)$

(10) Coordinate, prepare and maintain an Engineering Critical Component Specification - Part I for the following components, in accordance with the management and engineering principles delineated in the AFSCM 375 series of documents and exhibits:

a. Support Stem Assembly

b. Cluster Hot End Support Hardware

c. Cluster Assembly and Miscellaneous Hardware

d. Reflector and Axial support System

e. Ganged Drive System

f. Support Stem Feed and Discharge System

g. Shields

h. Lateral Support System

i. Core Periphery

j. Poison Wire System

k. Flight Diagnostic and Control Instrumentation System

1. Reactor Control System Iogic Portion of EPIC

m. Fuel Elements

The se specifications shall be in the format of, and include the technical content specified in the following AFSCM 310 Data Item:

a. C-10-46.0 Detail Specification (Critical Component) 
Project 1712 (Cont.)

(11) Coordinate, prepare and maintain, for each of the Engineering Critical Components listed in paragraph A.IO, the following documents. These documents are to be prepared in accordance with the management and engineering principles delineated in the AFSCM 375 series of documents and exhibits; and, shall be in the format of, and include the technical content of the following AFSCM 310 Data Items:

$$
\text { a. }(\mathrm{E}-105)(\mathrm{E}-106)(\mathrm{T}-102)(\mathrm{C}-26-64.0)(\mathrm{T}-119) \text { and }(\mathrm{S}-21)
$$

(12) Issue one (1) month after the conduct of the Nuclear Subsystem Contract End Item - Preliminary Design Review, for each of the Engineering Critical Components listed in paragraph A.10, the following:

a. Data Item (C-10-46.0)

b. Data Items $(E-105)(E-106)(T-102)$ and $(S-21)$

(13) Coordinate, prepare and maintain the Structural support Coolant Valve Actuator - Engineering Critical Component Specification Part I in accordance with the management and engineering principles delineated in the AFSCM 375 series of documents and exhibits. This specification shall be in the format of, and include the technical content specified in the following AFSCM 310 Data Item:

a. C-10-46.0 Detail Specification (Critical Component).

(14) Coordinate, prepare and maintain the following documents in accordance with the management and engineering principles delineated in the AFSCM 375 series of documents and exhibits for the structural Support Coolant Valve Actuator - Engineering Critical Component. The documents shall be in the format of, and include the technical content of, the following AFSCM 310 Data Items:

a. $(\mathrm{E}-105)(\mathrm{E}-106)(\mathrm{T}-102)(\mathrm{C}-26-64.0)(\mathrm{I}-2-17.0-2)(\mathrm{T}-119)$ and $(\mathrm{S}-2 \mathrm{l})$

(15) Issue one (1) month after the conduct of the Structural Support Coolant Valve and Actuator System - Contract End Item - Preliminary Design Review, for the Structural Support Coolant Valve Actuator Engineering Critical Component the following:

a. Data Item (C-10-46.0)

b. Data Items $(\mathrm{E}-105)(\mathrm{E}-106)(\mathrm{T}-102)(\mathrm{I}-2-17.0-2)$ and $(\mathrm{S}-2 \mathrm{I})$

(16) Review and approve the Structural Support Coolant Valve Piping and Support-Engineering Critical Component Specification - Part I prepared by AGC. 
Subtask 1.3 - Reactor System Integration

Project 1300 - Reactor Test Engineering - Technology

A. Engineering

(I) Maintain and modify, as required, the NRX-A6 Test Specification. Review and coordinate WAII comments and approval action for proposed modifications to the NRX-A6 Test Specification.

(2) Coordinate changes to the NRX-A6 Measurement Requirements List (MRI), and issue the MRI monthly, and then twice monthly throughout the test series.

(3) Review and coordinate WAIN coments and approval action on NRDS procedures for the assembly, operation, disassembly, and postoperative examination of $\mathrm{NRX}-\mathrm{A} 6$.

(4) Provide representation at NRDS during disassembly and postoperative examination of $\mathrm{NRX}-\mathrm{A} 6$.

(5) Direct and participate in the DRAGON Team effort for the NRX-A6 test.

(6) Coordinate and prepare an NRX-A6 Final Report.

(7) Provide technical support to NRDS in the planning and execution of the NRX-A6 test.

(8) Provide TS\&PRB and TRB representation at NRDS through NRX-A6.

B. Fabrication - Not applicable.

C. Testing - Not applicable.

D. Tooling - Not applicable. 
Subtask 1.3 - Reactor System Integration

Project 1311 - Reactor Test Engineering - Reactor

A. Engineering

(1) Coordinate and prepare the R-I Reactor Intermal Measurements (RIM) list and initiate preparation of the R-2 RIM. Issue the R-I RIM periodically, as required following SNPO-C approval.

(2) Follow the initial planning for the R-I test program.

(3) Follow the PHOEBUS II test program to factor PHOEBUS testing experience into the reactor test program.

(4) Support the preparation of the AFSCM 310 data items specified in Project 1172 and the NERVA Engine CEI Specification - Part I as appropriate.

B. Fabrication - Not applicable.

C. Testing - Not applicable.

D. Tooling - Not applicable. 
Subtask 1.3 - Reactor System Integration

\section{Project 1320 - Test Assembly Design - Technology}

A. Engineering

(1) Provide design and procurement follow-up for XE-2-mounted integraI nuclear detection system.

(2) Provide engineering input and review of $X E-1$ and $X E-2$ wiring schedules.

(3) Provide input into the $X E-1$ and $X E-2$ instrumentation interconnection drawing.

(4) Provide engineering input to, and review of, the XE-2 test plans, test specifications, NTO assembly, operating and testing procedures, WANL-AGC interface control drawing procedures and hardware schedules. Maintain technical liaison with other organizations.

(5) Provide engineering support to NTO during assembly and testing operations as required for $\mathrm{XE}-2$. Provide support for NRX-A6 and $\mathrm{XF}-1$ testing and disassembly.

(6) Initiate conceptual design of source-term sampling system for $\mathrm{XE}-2$.

B. Fabrication

(1) Procure and fabricate those items designed under A.I.

C. Testing - Not applicable.

D. Tooling - Not applicable. 
Subtask 1.3 - Reactor System Integration

Project 1321 - Test Assembly Design - Reactor

A. Engineering

(1) Conduct design reviews of the NRX and PHOEBUS-2A basic test cm: to determine modifications required to support the initial $0 \pm 1.1$. in the R-Reactor Program.

(2) Review those ACF drawings, specifications, and procedures required to perform Items (3), (4), and (5) below.

(3) Initiate conceptual design layouts of the basic $\mathrm{R}-1$ test assf n\} 1.'. Emphasis is to be placed on the interface area comprising t1.. reactor vessel support, pneumatic actuator, support coolant system, and privy roof. The conceptual layout of this area, will be completed.

(4) Conduct analytical design studies to determine the required unfiguration of the following $\mathrm{R}-1$ hardware:

a. Reactor support stand

b. SSCV test car piping system

c. Propellant line

(5) Complete analytical design studies to determine capability and identify required changes in the following test car components for use in the R-Reactor Program:

a. Privy roof

b. Flatbed weldment

c. Privy assembly

d. Outriggers

(6) Initiate stress analysis for WANL Code 1 and Code 2 test ass iy basic test car hardware.

(7) Initiate study of changes of Test Cell "C" $360^{\circ}$ shield tank assembly, as required.

(8) Provide engineering input and review of program requirementi, WANL-AGC interface control drawing procedures and hardware schedules. Maintain liaison with other groups, as required, for the basic test car.

(9) Initiate fabrication of analytical model to assist in reactor support stand design.

(10) Support the preparation of the AFSCM 310 Data Items specified in Project 1112 and the NERVA Engine CEI Specification - Part I, as appropriate. 
Project 1321 (Cont.)

B. Fabrication

(1) Procure and fabricate hardware designated in Paragraph A. (9).

C. Testing - Not applicable.

D. Tooling - Not applicable. 
Subtask 1.5 - Engine Controls

Project 1500 - Control System Design and Analysis - Technology

A. Engineering

(1) Prepare and maintain a program plan for the design and analysis of the XE-1 and XE-2 control systems.

(2) Complete the functional design of experimental controller for $\mathrm{XE}-1$ and $\mathrm{XE}-2$, and prepare the checkout procedure for $\mathrm{XE}-1$ controllers.

(3) Specify, evaluate, and implement simplified models of the XE system which can be used for control systems design.

(4) Review and approve the detailed control hardware designs, and provide the required coordination with all cognizant engineering groups.

(5) Assist in the installation and acceptance-testing of the control system.

(6) Provide the support necessary for the preparation of the test plans and test specifications.

(7) Design breadboard controllers to support the analog computer studies of the reactor systems.

(8) Provide required support for safety studies related to the test series.

(9) Provide technical support for dynamic data acquisition experiments.

(10) Develop required models for control mechanisms and other control hardware for use with the CAM models.

(11) Provide support of test operations and preparation of posttest control system reports.

(12) Support the development of engine nuclear instrumentation.

(13) Determine XE-2 test objectives required to develop reactor controls technology.

(14) Continue development of a method of reactor startup through the bootstrap without the use of nuclear instrumentation. 
Project 1500 (Cont.)

(15) Prepare and obtain AGC approval of functional requirements, functional designs, and engineering change requests for reactor controls.

(16) Obtain AGC approval of reactor control system detail designs.

(17) Provide input to, and assist in the preparation of, joint $\mathrm{XE}$ controls design reports.

B. Fabrication

(1) Fabricate breadboard controllers in accordance with functional designs for use with the analog computer analyses.

(2) Fabricate experimental circuits to check feasibility of circuit concepts.

C. Testing - Not applicable.

D. Tooling - Not applicable. 
Subtask 1.5 - Engine Controls

Project 1511 - Control System Design and Analysis - Reactor

A. Engineering

(1) Prepare and maintain a program plan for the analysis and desi $i n$ of the nuclear subsystem control system.

(2) Specify, evaluate, and implement simplified models of the nuclear subsystem which can be used for controls design.

(3) Conduct a program of analytical and experimental work which will lead to the definition of a simple and reliable Reactor control System configuration which satisfies the requirements developed in A. (2).

(4) Review and determine the required malfunction protection concepts for the nuclear subsystem test series. This will include preparing performance requirements for temperature sensing, actuators and nuclear instrumentation.

(5) Analyze methods of reactor startup to the level where the temperature loop can be closed without the use of nuclear instrumentation. Select a prime candidate for use for the nuclear subsystem.

(6) Develop required models for the drum actuators, drum coupling system, SSCV-SSBV actuator and valves system, and other controls hardware for use with the CAM models. This includes the required effort to become cognizant of all aspects of the CAM models.

(7) Design breadboard controllers to support the analog computer studies of the nuclear subsystem.

(8) Follow the control system effort at IASL including IASI work on the SSCV control systems and actuators planned for use in the PHOEBUS II test at Test Cell "C"; provide technical support for SSCV oriented tests on the PHOEBUS II reactor as required for nuclear subsystem development.

(9) Perform preliminary planning and design analysis of the reactor safety and diagnostic system.

(10) Support the preparation of the AFSCM 310 data items specified in Project 1112 and the NERVA engine CEI specification Part 1, as appropriate.

B. Fabrication - Not Applicable.

C. Testing - Not Applicable.

D. Tooling - Not Applicable. 
Subtask 1.5 - Engine Controls

Project 1520 - Control Actuators - Technology

A. Engineering

(1) Maintain a program plan and schedule for control drum actuator support for XE-1 and XE-2.

(2) Complete the procurement, assembly, and delivery of the control drum actuator subsystem for the XE-2 test series.

(3) Provide follow-up and field support to NTO for installation, checkout, and test-monitoring of the actuator subsystem for $X E-1$ and $X E-2$.

(4) Review and analyze performance test data to provide guidance for design modifications as needed and also as an important input to design effort for the NERVA reactor program.

(5) Prepare procedures for installation and checkout of actuators, drive shafts, pedestals, and amplifiers. Train and qualify NTO personnel in the assembly, use, and disassembly of this equipment.

(6) Provide post-test requirements for recovery, investigation, and examination to provide input information to follow-up program.

(7) Design test fixtures and test assemblies, as required.

(8) Support the acceptance and performance tests of the control drum actuator subsystem for the XE-2 series.

(9) Prepare documentation for, and conduct control drum actuator system design review.

B. Fabrication

(1) Fabricate test fixtures and test assemblies, as required.

C. Testing

(1) Perform development tests on the pneumatic actuator subsystem as needed to support the XE-2 test.

(2) Perform the environmental-testing of the XE-2 control drum actuator subsystem to verify qualified operations over the expected engineoperating environment range.

(3) Perform development tests, as needed, to support the environmental tests to obtain additional information needed for design modifications.

D. Tooling - Not Applicable. 
Subtask 1.5 - Engine Controls

Project 1521 - Control Actuators - Reactor

A. Engineering

(1) Maintain a program plan and schedule for control drum actuator and structural support coolant valve (SSCV) actuator subsyster.. development program.

(2) Conduct a search and survey of presently available actuators and system components that can be supplied with minimum modifications for the SSCV actuator subsystem.

(3) Proceed with the design and development as required to provide ganged drum control drum actuator subsystems for the R-l reactor test.

(4) Proceed with the design and development as required to provide SSCV actuator subsystems for the $R-1$ reactor test.

(5) Direct the procurement of preliminary actuator candidates to support the search and survey effort.

(6) Provide pre-test data review and analysis, test monitoring and post-test review and analysis for NRX-A6 side-by-side pneumatic actuator test.

(7) Design test fixtures, load impedances, input devices and test assemblies as required to support the development effort incluring ganged drum tests.

(8) Support the Lewis Labs irradiation tests for the $A G-20$, $\mathrm{YE}-1$ and $\mathrm{XE}-2$ pneumatic actuators.

(9) Support the preparation of the AFSCM 310 data items specitied in Project 1112 and the NERVA engine CEI Specification - Part I, as appropriate.

B. Fabrication

(1) Fabricate test fixtures and test assemblies as required to support the development program.

C. Testing

(1) Perform preliminary evaluation tests on the candidate subsystem components to provide support to the search and survey program.

(2) Perform preliminary ganged drum subsystem tests to verify conceptual designs.

(3) Perform servo-valve tests and other component tests to support the development program.

D. Tooling - Not Applicable. 
Subtask 1.5 - Engine Controls

Project 1530 - Electronic Development - Technology

A. Engineering

(1) Perform the detailed circuit and packaging design for the XE-2 Experimental Controller and TSCS modifications.

(2) Generate acceptance test specifications for the control equipment.

(3) Update and/or generate operational and malntenance manuals for the XE-2 experimental control equipment and TSCS modifications.

(4) Provide engineering follow during fabrication of deliverable hardware.

(5) Generate installation and checkout procedures for incorporation of modification into the ETS-I facility at NRDS.

(6) Support installation, checkout, and operation of WAINL delivered equipment at NRDS as required.

(7) Perform detailed circuit and packaging design for XE-I Experimental Controller Chassis No. 2.

(8) Generate acceptance test procedure and operational manuals for Experimental Control Chassis No. 2.

B. Fabrication

(1) Build breadboards necessary for equipment design.

(2) Build prototypes for control system modifications.

(3) Build test fixtures for acceptance testing.

C. Testing

(1) Conduct evaluation tests of the breadboard circuits.

(2) Conduct proof tests of the prototype equipment.

D. Tooling - Not Applicable. 
Subtask 1.5 - Engine Controls

Project 1531 - Electronic Development - Reactor

A. Engineering

(1) Design control circuitry as required to support the development of the ganged drum actuator system and SSCV actuator system.

(2) Initiate design and development of actuator amplifier circuits compatible with the developmental drum actuator and ganged system.

(3) Initiate design and development of actuator amplifier circuits compatible with the developmental SSCV actuators.

(4) Provide engineering support in the electronic area for the testing of the developmental control drum and SSCV actuator systems.

(5) Study the interaction effects of clustered engine configurations on nuclear power measurements and investigate the means of reducing this effect if necessary.

(6) Develop and/or procure nuclear detector systems compatible with engine clustering and conduct evaluation testing.

(7) Complete requirements for NSS actuation systems electronics and for the nuclear instrumentation system.

B. Fabrication

(1) Fabricate breadboards as required for electronics development.

(2) Fabricate control and test equipment as required to support development programs.

C. Testing

(1) Perform evaluation testing of breadboards.

D. Tooling - Not Applicable. 
Subtask 1.5 - Engine Controls

Project 1569 - Facility Engine Control System Design - Support

A. Engineering

(1) Prepare and maintain a program plan for the analysis and design of the facility control systems for $\mathrm{R}-1$ in Test Cell " $\mathrm{C}$ " and WANL modifications to the TSCS at ETS-l.

(2) Monitor the facility controls program in Test Cell "C" to insure that WANL is aware of all changes that might affect $R-1$ controls performance and maintain up to date schematics of the Test Cell " $\mathrm{C}$ " control system.

(3) Develop the required models and breadboards of facility control devices and other hardware for use with the R-I CAM. This includes the required effort to become cognizant of the $R-1$ CAM.

(4) Provide controls engineering support for NRX-A6 testing.

(5) Evaluate the existing TSCS control systems to determine their ability to meet $X E-1$ and $X E-2$ test objectives. Provide the design and analysis required to make the necessary modifications including preparation and obtaining AGC approval of functional requirements, functional designs, and engineering change requests.

(6) Conduct analyses leading to definition of the Test Cell "C" propellant control system for $\mathrm{R}-1$.

B. Fabrication - Not Applicable.

C. Testing - Not Applicable.

D. Tooling - Not Applicable. 
Subtask 1.7 - Instrumentation

Project 1720 - Instmumentation Components and Systems - Technology

Based on the IVERVA test schedules and on the measurement and performance requirements established by the Reactor Analysis, Reactor Control and Reactor Design Programs, procure, calibrate and maintain technical surveillance of reactor installation of instrumentation system transducer components whose analysis and/or qualification test results indicate their capability to satisfactorily perform when used in the diagnostic and control instrumentation systems of $\mathrm{NRX}$ and $\mathrm{XE}$ reactors. Analyze, evaluate and recommend modifications to the facility to ensure compatibility with the reactor measurement requirements and evaluate and report on instrumentation component and the measurement system performance. The following systems tests shall be considered during the contract period: $\mathrm{XECF}, \mathrm{XE}-\mathrm{I}, \mathrm{XE}-2, \mathrm{NRX}-\mathrm{A} 6$.

A. Engineering

(1) Prepare and issue instrument component specifications relative to disassembly. Maintain Instrument Systems, Reactor Design, Reactor Assembly, NRDS, IASL and AGC coordination.

(2) Select instrmentation transducer and transducer subsystem components for reactor test for Technology Reactor Program. Prepare MRI transducer information. Maintain coordination relative to measurement requirements with Test Engineering, Reactor Design, Reactor Analysis, Reactor Control, Instrument Systems and Instrument Committee.

(3) Conceive, initiate and review transducer and instrumentation system checkout and calibration techniques of reactor transducers at WANL and NRDS. Review and approve transducer installation and associated wiring drawings for the Technology Program. Maintain AGC, Ground Support Engineering, Instrument Systems Engineering and Reactor Design coordination.

(4) Calibrate instrumentation transducers and transducer subsystems as required to establish specific accuracies and error band data over the environmental temperature range for reactor use in XE-2. Provide transducer calibration and checkout specifications for use prior to and after reactor installation and test. Prepare transducer calibration data book compiling all operating characteristics of WANL supplied transducers for use in NRDS data system setup and reactor test data reduction and evaluation.

(5) Provide engineering support to Reactor Assembly during instrumentation installation and to NRDS during reactor preparation, test and posttest operations. Participate on the reactor and engine test data evaluation teams at NRDS and WANL to provide data interpretation and conclusions relative to measuring system performance.

(6) Evaluate and report significant results of transducer subsystem performance based on the analysis incident to instrumentation selection, upon the records reflecting the "as-built" configuration and upon the actual test recorded data. Based upon results of these instrumentation evaluations, establish criteria and present recommendations for additional transducer development and testing necessary to the future 
Project 1720 (Cont.)

selection of sensors to be used in reactor tests. Conduct and participate in reliability design reviews and component assessments.

(7) Perform reactor post-operation transducer checkout, application evaluation and calibration. Prepare final instrumentation transducer reports for $\mathrm{NRX}-\mathrm{A} 6$ and $\mathrm{XECF}$.

(8) Issue Error Band Limits Reports for WANL supplied measurements for engine system tests one month prior to each test.

B. Fabrication

(1) Assemble cables and splices as required in preparation of instrumentation for calibration and installation.

C. Testing

(1) Perform pre-installation testing. Perform calibration testing of reactor system transducers. Perform post-test calibration testing of selected transducers.

D. Tooling - Not applicable. 
Subtask 1.7 - Instrumentation

Project 1721 - Instrumentation Components and Systems - Reactor

Based on the test schedules and on the measurement and performance requirements established by the Reactor Analysis, Reactor Control and Reactor Design Programs select system transducer components whose analysis and/or qualification test results indicate their capability to satisfactorily perform when used in the diagnostic and control instrumentation systems of the R-l and E-1 reactor. Analyze, evaluate and recommend modifications to the facility to ensure compatibility with the reactor measurement requirements and data system. The following reactor instrumentation shall be considered during the contract period: $R-1$ and $E-I$.

\section{A. Engineering}

(1) Determine the minimum level of testing required as dictated by measurement requirements, environmental conditions and reactor installation design criteria which will qualify a candidate transducer for selection for the R-I and E-I application.

(2) Conceive and specify installation, test and application techniques to be used for the R-I and E-I transducer subsystems. Maintain Instrumentation Development, Instrument Systems, Reactor Design, Reactor Assembly, NRDS, LASI and AGC coordination.

(3) Select instrumentation transducer and transducer subsystem components for the $\mathrm{R}-1$ and $\mathrm{E}-1$ reactor test. Prepare MRI transducer information. Maintain Test Engineering, Reactor Design, Reactor Analysis, Reactor Control, Instrument Systems and Instrument Committee coordination relative to measurement requirements.

(4) Conceive and initiate transducer installation design for the R-I and E-I reactor and establish checkout techniques. Review and approve transducer installation and associated wiring drawings for the $\mathrm{R}-1$ and $E-1$ reactors. Maintain AGC, Ground Support Engineering, Instrument Systems Engineering and Reactor Design coordination.

(5) Specify the criteria for the special nuclear subsystem signal conditioning, referencing, amplifying, and demodulating equipment as needed for use with the EPIC system. Included will be:

a. Conception of demodulation techniques for conditioning LVDT, variable reluctance pressure transducers and variable reluctance accelerometers.

b. Conception of temperature referencing systems for cryogenic measurements in flight. 
Project 1721 (Cont.)

c. Conception of high-gain pre-amplifier circuitry for use with high-impedance instrumentation.

d. Conception of a means of reduction of all normal signal conditioning (strain gages, temperatures, SGPS, etc.) in size and weight. Efforts will be made to incorporate the signal conditioning function into the data system so that separate equipment is not required.

e. Conception of a means of reduction of all normal data amplification equipment in size and weight. Effort will be directed toward incorporation of the data amplification function and other portions of the data system so that separate equipment is not required.

(6) Support the preparation of the AFSCM 310 data items specified in Project 1112 and the NERVA engine CEI specification - Part I as appropriate.

B. Fabrication - Not applicable.

C. Testing - Not applicable.

D. Tooling - Not applicable. 
Subtask 1.7 - Instrumentation

Project 1769 - Instrumentation and EPIC Development - Support

A. Engineering

(1) Based on the measurement requirements of the muclear subsystem, initiate or continue the development of the following instrumentation:

a. Thermocouples for measurement of the core exit gas temperatures.

b. Displacement transducers for measurement of the magnitude of displacement of reactor components and control drum position.

(2) Design the test fixtures and the control and readout systems for the non-nuclear developmental and evaluation testing of instrumentation components. Furnish support to Radiation Effects activity in nuclear developmental and evaluation testing of instrumentation components.

(3) Coordinate WANL instmumentation development activities with those of AGC, Los Alamos, and other agencies working on similar or related problems.

(4) Participate in not more than two review meetings as required and issue minutes of these meetings to AGC and SNPO-C.

(5) Provide technical assistance for procurement of instrumentation.

(6) Prepare and issue to AGC/SNPO-C development program reports on all nuclear and non-nuclear instrumentation development conducted.

(7) Plan qualification tests of reactor grade instrument components when developmental test results indicate their capability of performing satisfactorily when used in diagnostic and/or control instrumentation systems in the nuclear subsystem tests.

(8) Prepare and issue to AGC/SNPO-C, and revise as necessary, qualification test specifications for each instmumentation component being developed for NERVA application.

(9) Perform vendor qualification tests of XE-2 exit gas thermocouples. 
Project 1769 (Cont.)

B. Fabrication

Test fixtures and special environment test chambers will be required to investigate instrument performance. WANL in-house designs will require the assembly of candidate instruments from procured components.

C. Testing

Testing will be planned, designed, and conducted for the purpose of meeting the requirements of specific reactors. This will include all non-nuclear developmental testing. In addition, nuclear testing of instruments will be conducted cooperatively with the Radiation Effects activity. Tests of a special nature may be required at various stages during the development program to investigate unpredictable problem areas.

D. Tooling - Not applicable. 
Subtask 1.8 - Systems Analysis

Project 1800 - Engine Systems Analysis - Technology

A. Engineering

(1) Conduct and report dynamic analyses by means of Common Analog Models of problems related to the behavior of the nuclear subsystem in the $\mathrm{XE}-1$ and $\mathrm{XE}-2$ test systems. In particular:

a. Prepare input to, review and evaluate the Test Plans and Test Specifications to ensure fulfillment of systems analysis objectives.

b. Prepare input to, review and approve the planned mun profiles and associated instrumentation (Measurement Requirement Lists) to ensure fulfillment of systems analysis objectives.

c. Participate in the planning, preparation, and review of the Test Prediction Reports.

(2) Maintain Common Analog Models of the XE physical systems which include: nuclear subsystem, engine and ETS-I feedsystems, and emergency systems. In particular:

a. Review and approve Interface Control Steady-State Predictions.

b. Develop and provide to AGC improvements in the dynamic models for the nuclear subsystem for use in the Common Analog Model. Development of the above model improvements will be on the basis of (1) experimental data comparisons, (2) analytical comparisons involving the use of both analog and digital techniques for validation of the models, including the comparison of alternate analysis models against the existing Common Analog Models.

c. Review changes to the engine feedsystem and emergency system equations provided by AGC and incorporate in the XE Common Analog Models as appropriate.

d. Run common problems on a regular basis and participate with $\mathrm{AGC}$ in a comparison of results to provide a cross check of the AGC and WANL implementation of the Common Analog Models.

e. Provide inputs to and review reports on the final $X E-1$ and XE-2 Common Analog Models. 
(3) Plan, analyze, and coordinate with AGC and NTO, as appropriate, the execution of special system dynamics measurements for XE-1 and $\mathrm{XE}-2$ tests, including specification of required instmmentation and computer prediction of expected results to assure meeting test objectives. Process and analyze the XE-1 data for use in model upgrading. Continue updating of processing codes and of advanced techniques for making such measurements. Issue reports on results of such measurements in XE-I.

(4) Participate in data system and test data review activities during tests.

(5) Convert selected wideband data taken during XE testing to oscillograph records and to digital signals suitable for digital computer processing for WANL use. Generate digital plots and listings of appropriate wideband data for WANL use.

(6) Develop special codes for post-test analysis of transient test data from the $\mathrm{XE}-1$ and $\mathrm{XE}-2$ tests. Analyze the test data to establish internal consistency of the data, to evaluate nuclear subsystem dynamic performance during the tests, and to determine the adequacy of the predictions of the Common Analog Models. Issue reports on the XE-I transient data analysis.

(7) Assist in conducting analysis to support the design and development of the $X E-1$ and $X E-2$ reactor control systems.

(8) Assist in predicting control performance of the XF systems during tests, including transient startups, by means of the Common Analog Models.

(9) Provide input to XE-I Final Test Report.

(10) Document and maintain files of analytical and experimental data utilized in relation to these tasks.

(11) Support the operation and maintenance of the hybrid computer facility as it relates to these tasks.

(12) Assist in evaluating potential nuclear subsystem operational problems and hazards during both normal and abnormal operations of engine tests and analyze appropriate countermeasures with emphasis on the nuclear subsystem. Perform these dynamics analyses with a digital computer implementation of the XE-1 system.

B. Fabrication - Not applicable.

C. Testing - Not applicable.

D. Tooling - Not applicable. 
Subtask 1.8 - Systems Analysis

Project 1812 - Engine Systems Analysis - Engine

A. Engineering

(1) Maintain digital implementation of the Common Model of the NERVA engine physical systems which include: nuclear subsystem, engine feedsystem, ETS-l feedsystem, and emergency systems. In particular:

a. Develop and provide to AGC improvements in the dynamic models for the nuclear subsystem for use in the Common Analog Models. Development of the above model improvements will be on the basis of (I) experimental data comparisons and (2) analytical comparisons involving the use of both analog and digital techniques for validation of the models, including the comparison of alternate analysis models, against the existing Common Analog Models.

b. Run digital check problems on a regular basis and participate with AGC in a comparison of results to provide a cross check of the AGC implementation of the Common Analog Models.

c. Provide inputs to and review reports on the NERVA Engine Common Analog Models.

(2) Develop and upgrade required dynamic models and perform computer analyses of the consequences of mission aborts resulting from various system malfunctions, considering the effects of various proposed countermeasures, in support of the flight safety activity.

(3) Assist in conducting analyses to support the design and development of the engine reactor control systems.

(4) Support the preparation of the AFSCM 310 data items specified in Project 1112 and the NERVA Engine CEI Specification - Part I as appropriate.

B. Fabrication - Not applicable.

C. Testing - Not applicable.

D. Tooling - Not applicable. 
Subtask 1.8 - Systems Analysis

Project 1820 - Reactor Systems Analysis - Technology

\section{A. Engineering}

(1) Conduct and report dynamic analyses by means of Common Analog Models of behavior of the NRX-A6 test systems. In particular:

a. Prepare input to, review and evaluate the Test Specifications to ensure fulfillment of systems analysis objectives.

b. Prepare inputs to, review and approve the planned run profiles to ensure fulfillment of systems analysis objectives.

c. Perform dynamic analyses of the run profiles as required to assure that reactor system operating constraints are not exceeded.

d. Assist in evaluating potential nuclear subsystem operational problems and hazards during both normal and abnormal operations of NRX-A6 tests and analyze appropriate countermeasures.

e. Participate in the planning, input preparation, review and issuance of the Test Predictions Reports.

(2) Maintain Common Analog Models of the NRX-A6 physical system which include: nuclear subsystem, thrust nozzle, Test Cell "C" feedsystem, and emergency systems. In particular:

a. Review and approve Interface Control Steady State Predictions.

b. Develop and provide to AGC improvements in the dynamic models for the nuclear subsystem, the Test Cell "C" feedsystem, and the emergency systems for inclusion in the Common Analog Models. Development of the above model improvements will be on the basis of (1) experimental data comparisons and (2) analytical comparisons involving the use of both analog and digital techniques for validation of the models, including the comparison of alternate analysis models against the existing Common Analog Models.

c. Review changes to the nozzle equations provided by AGC and incorporate in the NRX Common Analog Models as appropriate.

d. Run common problems on a regular basis and participate with AGC in a comparison of results to provide a cross check of the AGC and WANL implementation of the Common Analog Model.

e. Continue development of improved computer techniques for implementation of Common Analog Models. 


\section{Project 1820 (Cont.)}

(3) Participate in data system and test data review activities during the NRX-A6 tests.

(4) Develop special codes for post-test analysis of transient test data from the NRX-A6 tests. Analyze the data to establish internal consistency of the data, to evaluate the dynamic performance of the nuclear subsystem, facility feedsystem, and emergency systems during the tests, and to determine the adequacy of the predictions of the Common Analog Model. Issue report on the analyses of the NRX-A6 transient test data.

(5) Convert selected wide band data taken during NRX testing to oscillograph records and, on a limited basis, to digital signals for computer processing.

(6) Provide data for the Final Reports on the NRX-A6 tests.

(7) Assist in conducting analysis to support the design and development of the NRX-A6 reactor control systems.

(8) Assist in predicting control performance of the NRX systems during tests, including transient startups, by means of the Common Analog Models.

(9) Assist in conducting computer studies to determine the effect of malfunctions of the reactor control system during NRX-A6 tests.

(10) Perform control subsystem and control system tests on the analog computer using specification grade hardware.

(11) Support the operation and maintenance of the hybrid computer facility as it relates to these tasks.

(12) Document and maintain files of analytical and experimental data utilized in relation to these tasks.

B. Fabrication - Not applicable.

C. Testing - Not applicable.

D. Tooling - Not applicable. 
Subtask 1.8 - Systems Analysis

Project 1831 - Reactor Systems Analysis - Reactor

A. Engineering

(1) Maintain Common Analog Models of the NERVA reactor physical system which include: nuclear subsystem, thrust nozzle, Test Cell "C" feedsystem and emergency systems. In particular:

a. Develop and provide to AGC improvements in the dynamic models for the nuclear subsystem, Test Cell "C" feedsystem, and emergency systems for inclusion in the Common Analog Models. Development of the above model improvements will be on the basis of (1) experimental data comparisons, including PHOEBUS IIA data, and (2) analytical comparisons involving the use of both analog and digital techniques for validation of the models, including the comparison of alternate analysis models against the existing Common Analog Model.

b. Review changes to the nozzle models provided by AGC for use in the R-I Common Analog Models.

c. Run digital check problems on a regular basis and participate with AGC in a comparison of results to provide a cross check of the WANL implementation of the R-I Common Analog Models.

d. Continue development of improved computer techniques for implementation of NERVA Reactor Common Analog Models.

(2) Assist in conducting analyses to support the design and development of the nuclear subsystem control system.

(3) Support the operation and maintenance of the hybrid computer facility as it relates to these tasks.

(4) Document and maintain files of analytical and experimental data utilized in relation to these tasks.

(5) Support the preparation of the AFSCM 310 data items specified in Project 1112 and the NERVA Engine CEI Specification - Part I as appropriate.

B. Fabrication - Not applicable.

C. Testing - Not applicable.

D. Tooling - Not applicable. 
Subtask 1.9 - Radiation Effects Program

Project 1909 - (U) Radiation Effects - Integration, Analysis, and Documentation - Support

\section{A. Engineering}

(1) Provide radiation effects analysis and consulting services in support of NERVA nuclear subsystem activities.

(2) Prepare and submit planning and analyses for radiation effects experiments to AGC and SNPO-C for review.

(3) Coordinate and schedule radiation effects tests.

(4) Provide documentation as follows:

a. Test plans and schedule to AGC for inclusion in the CY 1968 Radiation Effects Program Planning Document.

b. Test specifications, a design manual, and a safety analysis for Plum Brook for the performance of one shield material test in the $\mathrm{W}-2$ water loop.

c. Test specification for one materials test utilizing NARF and including the following materials: Shield Material

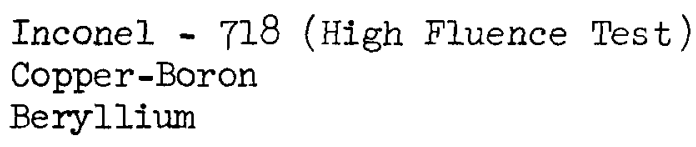

d. Test specifications for one LVDT instrumentation test in the NARF ASTR.

e. Flash report following the irradiation phase of each test.

f. Monthly letter status report.

g. Co-author or provide concurrence in the preparation of all subcontractor radiation effects documentation.

(5) Provide letter reports on pertinent radiation effects on nonfuel components in each NERVA and PHOEBUS test.

(6) Design a fixture for one shield materials test to be conducted

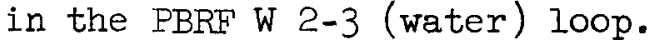

(7) Initiate and follow fabrication and/or procurement of hardware and fixtures for Items A.(6). 
Project 1909 (Cont.)

B. Fabrication

(1) Fabricate a fixture for the materials test commensurate with A. (6) above.

C. Testing - Not applicable.

D. Tooling - Not applicable. 
Subtask 1.9 - Radiation Effects Program

Project 1989 - Plum Brook Operations and Test Equipment Support - Support

A. Engineering

(I) Maintain a personnel staffing level equivalent to 2 engineers and 2 technicians until February 29, 1968. This staff shall provide the services required to conduct the tests and to administer property control functions. Tasks to be performed to the level of this manpower to include the following:

a. Provide assistance to Lewis Research Center for the performance of one thermionic test.

b. Conduct WANL shield materials irradiation and assist with postirradiation testing activities.

c. Provide necessary assistance to NASA PBRF personnel for operation and maintenance of the HT-I insertion machine.

d. Provide an inventory of all equipment materials and spare parts (Project 1900 series) located at the PBRF and at WANL, Large, Pa.

e. Inventory all documents, files, drawings, etc., at Plum Brook and at Large, $\mathrm{Pa}$. , concerming WANL activities and responsibilities at the PBRF.

f. Accumulate and file all engineering design data, drawings, sketches, and analyses pertaining to the modifications incorporated in the PBRF, as well as modifications that were started but not completed.

g. Complete and publish operating instructions for the W-I cryogenic loop, the $\mathrm{W}-2 / 3 \mathrm{loop}$, and the $\mathrm{HT}-1$ insertion machine.

h. Provide engineering support as required to aid in the performance evaluation and checkout of the $W-l$ facility (Contract SNPC-20). This assistance shall include the performance and acceptance testing of the $\mathrm{W}-1$ facility, review of as-built drawings, and provision for quality control documentation.

(2) During October and November 1967 continue the required engineering design activities and procurement and provide a status description of proposed modifications to the $W-1$ loop and associated equipment. Tasks to be included are the following:

a. W-1 Capsule Weights

b. Hot Cave Sleeve Valve Interlock

c. Hot Cave Support Cradle

d. Capsule Alignment Arm and Arm Lift Modifications 
Project 1989 (Cont.)

e. Installation of Absolute Helium Filter

f. Installation of Radiation Monitors

g. W-I Loop Capsule over Temperature Protection

h. Experiment Transfer Equipment

i. W-I Capsule Orientation Blocks

B. Fabrication - Not applicable.

C. Testing - Not applicable. 
Subtask 2.1 - Mechanical Ground Support Equipment

Project 2100 - Mechanical Ground Support Equipment - Technology

A. Engineering

(1) Complete final design of the following XE-l/XE-2 equipment:

a. Fuel Element Trays

b. Library Poison

c. Specimen Illumination Lighting

d. Storage Container Support Tables

e. FEPS Installation Hardware resulting from installation and checkout

f. Poison Wire Retraction Cups

(2) Continue design of the following equipment required to support PEWEE operations in E-MAD within the level of effort provided for this project. This design will consider maximum utilization of R-MAD equipment and IASL technical support.

a. Two point gamma scan (including gross gamma scan and boat conveyor)

b. PDP-8 Computer

c. INSIPID using Kollmorgen

d. MULE

e. WIPE

f. X-Ray

g. BAT

(3) Provide engineering support to NTO during NRX-A6 and XE-1 during hot disassembly and post-operative examinations.

(4) Provide engineering support for review of NTO procedures and test specifications. 
Project 2100 (Cont.)

(5) Conduct engineering liaison with other organizations, as required.

(6) Provide engineering support for XE-2 shipping.

(7) Initiate procurement of storage equipment for XE-2.

(8) Provide engineering support for XE-1 FEPS installation.

(9) Participate in Support Equipment Management meetings.

(10) Provide engineering support for installation of supplied ground support equipment at E-MAD, including modifications of RHD and POE, as required.

(11) Provide input to the XE-2 Operational Support Plan and Provisioning list (One issue this year).

B. Fabrication

(1) Complete fabrication of Items (1)a, b, c, d, e, and $f$.

C. Testing - Not applicable.

D. Tooling - Not applicable. 
Subtask 2.1 - Mechanical Ground Support Equipment

Project 2119 - Mechanical Ground Support Equipment - Support

A. Engineering

(I) Review $\mathrm{R}-1$ reactor design concepts to determine disassembly capability.

(2) Initiate layouts of major disassembly tooling as part of studies in disassembly methods.

(3) Support the preparation of the AFSCM 310 data items specific in Project 1112 and the NERVA Engine Specification - Part I as appropriate.

B. Fabrication - Not Applicable.

C. Testing - Not Applicable.

D. Tooling - Not Applicable. 
Subtask 2.1 - Mechanical Ground Support Equipment

Project 2120 - Tube Trailer Maintenance - Technology

A. Engineering

(1) Maintain and repair Government-owned helium tube trailers including valves and fittings.

a. Perform touch-up painting.

b. Provide two complete semi-annual inspections.

c. Monitor condition of each trailer.

d. Provide trailer maintenance and repair.

e. Maintain a list of trailers with the current hydrotest date and notify SNPO-C three (3) months prior to expiration of such date (five years from the last test) by date and trailer serial number in order to provide for scheduling of hydrostatic testing by the Government.

B. Fabrication - Not applicable.

C. Testing - As required to accomplish trailer maintenance.

D. Tooling - Not applicable. 
Subtask 2.2 - Electrical Ground Support Equipment

Project 2200 - Electrical Ground Support Equipment - Technology

A. Engineering

(1) Modernize and update existing electrical and electronic ground support equipment to aid in automatic checkout and verification of operational-readiness of the reactor portions of the test article. Provide operating instructions and documentation.

(2) Design a demodulator unit for the Transducer Test Equipment to facilitate checkout of reactor-installed-carrier transducers such as LVDT's, variable reluctance pressure transducers, and accelerometers.

(3) Design modifications required to insure usability of the following:

a. Transducer Test Equipment

b. Car Wiring Checker

c. Neff Amplifier Testing

d. Hyaraulic Actuator Checker

e. Pneumatic Actuator Checker

f. Corrosion Digitizer Equipment

(4) Provide service engineering for the ground support equipment at NRDS as follows:

a. Transducer Test Equipment

b. Car Wiring Checker

c. Neff Amplifier Tester

d. Hydraulic Actuator Checker

e. Pneumatic Actuator Checker

f. Corrosion Digitizer Equipment

(5) Establish design requirements for modifications to existing electrical ground support equipment required to insure usability for XE-2.

B. Fabrication - As Necessary.

C. Testing - Not Applicable.

D. Tooling - Not Applicable. 
Subtask 2.5 - Ground Operations Safety

Project 2509 - Ground Operations Safety - Support

A. Engineering

(1) Evaluate data, conduct analyses, and prepare nuclear safety reports in connection with the following operations:

a. Low power critical experiments at WANEF.

b. Fuel material development, manufacturing, hand ling, corrosion testing and storage conducted within WANL facilities.

c. Storage, shipment, assembly and disassembly of fuel modules and reactor cores.

(2) Review operating procedures and specify countermeasures to permit safe operation in the above areas.

(3) Initiate the safety documentation required for installation and operation of the $\mathrm{R} / \mathrm{E}$ critical experiments and the NCX at WAINEF.

(4) Continue safety analyses and issue, jointly with AGC, the XE-1 SER and Supplements to it as required to support XE-1 testing. Review $\mathrm{XE}-1$ assembly and operating procedures. Prepare source term predictions for both normal operation and accident conditions for the SNPO-N Scientific Advisory Panel.

(5) Prepare jointly with AGC, the nuclear safety documentation required for $X E-2$ testing, including the XE-2 Safety Evaluation Report and the XE-2 Operating Iimits Document. Review the XE-2 Test Specification and modifications to it. Review the XE-2 assembly and operating procedures. Prepare source term prediction for both normal operations and accident conditions for the SNPO-N Scientific Advisory Panel.

(6) Continue supplementary safety analyses and issue Supplements to the NRX-A6-SER as required. Review NRX-A6 operating procedures.

(7) Support the WANL Nuclear Safety Committee and perform periodic safety audits of WANEF operations. Provide participation on the Safety Review Committee established for monitoring the reactor and engine operation at NRDS.

B. Fabrication - Not applicable.

C. Testing - Not applicable.

D. Tooling - Not applicable. 
Subtask 2.5 - Ground Operations Safety

Project 2517 - Ground Operations Safety - NRDS

As part of NTO assist in performing the following functions:

A. Engineering

(1) Provide the necessary health and safety services for NERVA Test Operations at NRDS. This includes establishment of: safety procedures and regulations for all aspects of site contract operations, a functional health and safety program, liaison and coordination with federal, state, and local government agencies, and requirements for health and safety education and training in conjunction with Project 7017, selection of portable safety instrumentation and procedures for personal protection.

(2) Assist in the establishment of failure mode analysis, the safety evaluation of procedures and engineering documentation covering the conduct of operations, as well as the safety review of plans and specifications for new facilities and modifications of existing facilities at NRDS.

(3) Provide safety direction of the support services contractor's personnel assigned to the safety program.

B. Fabrication - Not applicable.

C. Testing - Not applicable.

D. Tooling - Not applicable. 
Subtask 2.6 - Product Assurance

Project 2609 - Reliability - Support

A. Engineering

Conduct a reliability program in support of the NERVA Program. This program will be conducted in accordance with section II of WANL-TINR-088, Rev.F, "NERVA Nuclear Subsystem Product Assurance Program Plan."

B. Fabrication - Not applicable.

C. Testing - Not applicable.

D. Tooling - Not applicable. 
Subtask 2.6 - Product Assurance

Project 2610 - WANL Quality Control - Technology

A. Engineering

Conduct a quality program in support of the NERVA Technology Program. This program will be conducted in accordance with the NERVA Nuclear Subsystem Product Assurance Program Plan, WANL-TNR-088, Rev.F.

B. Fabrication - Not applicable.

C. Testing - Not applicable.

D. Tooling - Not applicable. 
Subtask 2.6 - Product Assurance

Project 2611 - WAIN Quality Control - Reactor

A. Engineering

Conduct a quality control program in support of the NERVA Program. It will be accomplished in accordance with WANL-TNR-088, Rev.F, "NERVA Nuclear Subsystem Product Assurance Program Plan."

B. Fabrication - Not applicable.

C. Testing - Not applicable.

D. Tooling - Not applicable. 
Subtask 2.6 - Product Assurance

Project 2616 - WANL Quality Control - PEWEE

A. Engineering

Conduct a quality control program in support of the PEWEE Program. It will be accomplished in accordance with WANL-TNR-088, Rev. F, "NERVA Nuclear Subsystem Product Assurance Program Plan."

B. Fabrication - Not applicable.

C. Testing - Not applicable.

D. Tooling - Not applicable. 
Subtask 2.6 - Product Assurance

Project 2637 - Quality Control - AEC - NRDS

A. Engineering

(1) As a part of the NERVA Test Operations (NTO), product assurance program, perform reliability and quality assurance functions in accordance with applicable provisions of AGC Report 2469, Revision D, and WANL TNR-088, Revision F, as interpreted by the NTO Reliability and Quality Assurance Program Plan, NIO-A-0013.

B. Fabrication - Not applicable.

C. Testing - Not applicable.

D. Tooling - Not applicable. 
Subtask 2.7 - Flight Malfunction Studies

\section{Project 2700 Malfunction Studies - Technology}

A. Engineering

(1) Adapt the post-operational heating computer program for the NERVA reactor. Recommend, in cooperation with Advanced Reactor Design personnel, reactor design changes which will serve to enhance reactor integrity following selected malfunctions. Incorporate these changes into the post-operational heating computer program and assess their efficacy in enhancing core integrity.

(2) Examine selected system malfunctions which will lead to inability of the flight system to complete its mission objectives. Perform system analyses to define the condition of the reactor under these malfunction conditions. Perform post-operational heating studies, if appropriate, to define the condition of the reactor subsequent to these malfunctions, assuming no countermeasure action is taken. As required, examine emergency coolant requirements.

(3) Complete analyses of mechanical and functional criteria for the anti-criticality poison system (ACPS). Perform studies of operational procedures which, in conjunction with ACPS, will serve to enhance flight safety.

(4) Develop in cooperation with AGC Flight Safety personnel an overall integrated Flight Safety program for PFRT.

(5) Participate in the meetings and activities of the ROVER flight safety panels.

(6) Continue compilation of an updated source term program.

(7) Issue a report on post-operational heating and malfunction studies including results of analyses of design modifications.

(8) Issue a report on ACPS requirements.

B. Fabrication - Not applicable.

C. Testing - Not applicable.

D. Tooling - Not applicable. 
Project 2710 - Fission Product Diffusion Study - Technology

A. Engineering

(1) Update and modify the existing FIPDIF computer code as required using data from $\mathrm{NRX}$ and $\mathrm{XE}$ runs and other applicable laboratory data.

(2) Conduct radiochemical analyses of samples of effluent obtained by aircraft or other means during $\mathrm{NRX}$ and $\mathrm{XE}$ testing. Conduct post-operative radiochemical analyses of selected fuel element samples from these tests for the determination of total fissions, fission product losses, and aliquot factors for effluent samples.

(3) Investigate combining fuel element corrosion data from NRX and $X E$ tests and from corrosion tests into the existing source term prediction program.

(4) Issue an interim report on fission product release and source term following each NRX and XE test.

B. Fabrication - Not applicable.

C. Testing

(1) Perform laboratory analyses of reactor effluent samples collected from reactor tests.

D. Tooling - Not applicable. 
Subta.sk 2.8 - Non-Graphite Materials

Project 2800 - Non-Fuel Materials Planning, Design, Review, and Data Reporting - Technology

\section{A. Engineering}

(1) Plan, organize, and supervise the activities in this project.

(2) Prepare, revise, and maintain pertinent records for materials, process, and equipment specifications; review and submit materials test specifications and procedures to AGC and SNPO-C for approval.

(3) Review and approve NERVA reactor engineering drawings and participate in and attend design reviews to assure adequacy of materials and processes for reactor and support activities.

(4) Provide consultation on materials problems including post-mortem studies to other functional groups, particularly Reactor Mechanical Design, Reactor Analysis, Manufacturing, Purchasing, Quality Control, and Reactor Assembly.

(5) Collect, collate, compile, and provide AGC with evaluated and selected materials properties data quarterly for incorporation in the NERVA Materials Properties Data Book, which is to be used in design.

(6) Develop techniques to produce boron and/or boron carbide anticriticality poison wires.

(7) Select material for the flight shield; study processing characteristics of material; and develop manufacturing process.

(8) Perform design studies and tests to evaluate NERVA reactor materials behavior in space envirorments.

(9) Plan, evaluate, and report on the materials irradiation program to determine the effects of gamma and neutron irradiation on the mechanical and physical properties of NERVA materials in order to establish the adequacy of these materials.

(10) Develop processes for brazing orifices into fuel elements.

(11) Develop processing techniques for copper-boron ${ }^{10}$ control plates and cluster plates; determine mechanical and physical properties and uniformity of dispersion of boron 1

(12) Provide effort to develop methods of fabrication of support stems.

(13) Prepare an example of a Materials Verification List on one reactor component. 
Project 2800 (Cont.)

(14) Plan and coordinate the fuel out-gassing studies at $Y-12$, and provide analytical studies of the partial pressures and species of gases in the reactor during space travel.

B. Fabrication

(1) Machine test specimens and holding and mechanical loading fixtures for the experimental programs outlined above.

(2) Heat treat metal structures as indicated above in experimental program.

(3) Compact, sinter, forge, and extrude materials as described above in experimental program.

C. Testing

(1) Conduct mechanical, physical, metallographic, and space-environmental effects tests of materials as indicated in experimental program.

D. Tooling - Not applicable. 
Subtask 2.9 - Assistance to IA.SL

Project 2906 - Assistance to IASI - PEWEE

Provide a degree of assistance to IASL compatible with the funding provided for this project in the design and analysis of fuel cluster experiments for the PEWEE reactors.

A. Engineering

(1) Define the fuel cluster configuration and coordinate the mechanical interfaces for the fuel cluster experiments with IASI on a continuing basis.

(2) Complete and release detail drawings for selected fuel cluster experiments.

(3) Coordinate the technical requirements of the experiments with IAST on a continuing basis.

B. Fabrication - Not applicable.

C. Testing - Not applicable.

D. Tooling - Not applicable. 
Subtask 2.9 - Assistance to IASL

Project 2900 - Assistance to IASL - Technology

A. Engineering

(1) Provide technical assistance to the Ios Alamos Scientific Laboratory at Los Alamos through June 30, 1968.

B. Fabrication - Not applicable.

C. Testing - Not applicable.

D. Tooling - Not applicable. 
Subtask 4.1 - Program Planning

Project 4100 - Program Planning \& Control - Technology

A. Engineering

(1) Provide for the planning, evaluation, control and continuous surveillance of the Nuclear Subsystem Program schedules.

(2) Conduct a PERT planning and status reporting operation in support of Paragraph A.(1). The PERT system shall be utilized and implemented in accordance with the NASA - PERT Time II Handbook dated October 30, 1966. Network diagrams which reflect the subcontractor's actual plan of action for accomplishing the tasks, valid and timely input for updating the networks, comprehensive narrative reports and computer printouts will be provided as defined herein. The activities planned for the near future (approximately one year) shall be covered in appropriate detail. The existing network for the $\mathrm{XF}-2$ shall serve as a model for determining the level of detail. Those activities that are in the distant future, and are not clearly defined shall be structured at a gross level of detail. On a quarterly basis, those future activities originally structured at a gross level of detail shall be expanded as necessary to the appropriate level of detail. All networks shall be conveyed to SNPO-C and AGC concurrently.

a. Program Plan Management Networks.

1) The detailed end-item oriented PERT Program Plan Management Network for NRX and XE nuclear subsystems developed during the previous contract year shall be updated as required.

2) End-item oriented Program Plan Management Networks for the nuclear subsystem for the following test articles shall be developed and updated as required:
a) $R-1$
b) $\mathrm{E}-1$
c) $\mathrm{R}-2$

3) End-item oriented Program Plan Management Networks for the following test articles shall be developed and updated as required:
a) $\mathrm{PW}-1$
b) $\mathrm{PW}-2$ 
4) Program Plan Management Networks for the critical components and contract end-items delineated in Project 1112 shall be developed and updated.

5) The NERVA Reactor, Engine, CEI and CC network, shall be end-item oriented and shall consist of the following:

a) Engineering, design, analysis, procurement, fabrication, assembly, testing activities and the GSE and facility modifications required to support the test article assembly, testing and post-mortem operations.

b) The Configuration Management events and activities associated with the management and engineering principles delineated in the AFSCM 375 series of documents and exhibits.

c) Detailed activities which clearly define the NRDS effort for the reactor test articles and very gross NRDS activities for the engine test articles.

d) Logic interfaces with the reactor, engine, CEI, and CC networks prepared by the contractor.

e) Logic interfaces between test articles CEI's and CC's.

6) The PERT event designated as "Start First Power Test" shall be the reference for assessing the criticality of all activities associated or interrelated with the reactor and engine networks.

b. Reporting.

Biweekly PERT reports for all activities structured in the networks specified in paragraph $\mathrm{A}(2)$ a shall be prepared.

I) The biweekly PERT reports shall include the following sections :

a) Section 1 - Computer input data.

b) Section 2 - Narrative analysis.

c) Section 3 - Computer printout.

2) The sections shall be prepared and submitted, as required, to be received by SNPO-C and AGC in accordance with the following schedule:

a) Section 1 - on alternate Fridays (the reporting date).

b) Section 2 - on the Monday following the Friday reporting date.

c) Section 3 - on alternate Fridays (the reporting date). 
Project 4100 (Cont.)

3) Section 1 - Computer Input Data - Computer input data shall be submitted for all the subcontractor's activities structured in the networks and all the NRDS activities associated with the reactor and engine test articles. The computer input data shall be current as of the Wednesday preceding the Friday reporting date. Computer input data cards, and a computer generated listing of changes (or listing in accordance with the NASA Form 577 format) shall be submitted. The computer input data shall include the following information:

a) Status of all activities whose expected completion date was passed during a given biweekly report period. If an activity was completed, the actual completion date shall be stated. If an activity was not completed, the re-estimated activity time shall be stated.

b) Deleted activities.

c) New activities.

d) Revision of time estimates for activities in process or future activities shall be reported to provide data for best assessment of project status.

4) Section 2 - Narrative Analysis - An analysis of the subcontractor's work program shall be made including the impact of the NRDS activities associated with the reactor and engine test articles. The minimum information to be conveyed in the narrative section shall include the following:

a) A concise assessment of the outlook for meeting the significant and major milestone dates.

b) An indication of the change in outlook from the previous report and the reasons for the change.

c) An explanation stating the reasons (i.e., the technical and/or administrative problem, etc.) for time estimate changes and/or logic changes since the previous report for all activities on positive slack paths of one week or less, and on any negative (critical) slack paths.

d) A brief explanation stating the reasons for time estimate changes for all activities on positive slack paths of one week or less which were expected to be completed during the current report period but were rescheduled for completion beyond the report period. 
Project 4100 (Cont.)

e) Corrective action undertaken to effect schedule recovery relative to slippages reported in the previous report.

f) Corrective action planned to be taken as a result of the information obtained and incorporated in the current report to correct any further potential slippages.

g) Any additional information required for a clearer understanding of the events and status being reported.

5) Section 3 - Computer Printout - The computer printout shall include successor sorts, expected date sorts, critical sorts and master schedule sorts. The content of the master schedule sort shall be established by SNPO-C.

(3) Prepare and submit weekly a Significant Events Report covering the pertinent events of the preceding week. This report will include the overall programmatic events and the status of the major developmental tests.

(4) Provide program planning activities as follows:

a. Submit Contract Year 1968 and Contract Year 1969 proposals in response to $\mathrm{AGC}$ request (guidelines, change notices, requests for proposals). These proposals will consist of a program plan for all projects of the NERVA nuclear subsystem or selected projects as appropriate. Proposals will be submitted within sixty days of receipt of change notices and within forty-five days of receipt of guidelines or request for proposal.

b. Maintain and communicate to AGC and SNPO the current Contract Year 1968 Work Program Plan for each project of the NERVA Nuclear Subsystem.

c. Submit, on an annual basis, Schedule 189, describing the NERVA Nuclear Subsystem effort for fiscal years 1968, 1969 and 1970.

d. Submit Government-furnished Property requirements to support proposed CY 1968 and CY 1969 program plans.

(5) Prepare and submit a milestone chart for each project and a chart identifying the major program milestones upon which the work program is predicated. The milestone charts shall identify the planned accomplishments for the current contract year and the subsequent two contract years. The planned accomplishments for the current contract year shall be identified in detail and the 
Project 4100 (Cont.)

planned or projected accomplishments for the future contract years shall be identified in lesser detail. The milestone charts shall be submitted within 30 days after completing the work statement and estimated cost negotiation at the beginning of the contract year. In addition, updated milestone charts for projects reflecting milestone changes as a result of budget changes shall be submitted within 30 days following a renegotiation or the submittal of a budget run depicting internal reprograming.

B. Fabrication - Not applicable.

C. Testing - Not applicable.

D. Tooling - Not applicable. 
Subtask 4.2 - Fiscal Control

Project 4200 - Fiscal Control - Technology

A. Engineering

(1) Prepare and submit to AGC and SNPO-C the following fiscal reports :

a. Monthly incurred cost estimate.

1) Prepare and submit to AGC by 3:00 P.M. Sacramento time on the third working day of the month, an incurred cost estimate for the preceding month by NASA system numbers for NASA and AEC expenditures. (If delivered by telephone, confirm by letter.)

b. Monthly fiscal reports.

1) Prepare and submit monthly fiscal reports consistent with Westinghouse Accounting procedures, generally accepted accounting principles and practices appropriate to the particular circumstances, and AGC and SNPO-C reporting requirements showing expenditures by mutually selected projects and budget categories on the tenth calendar day of the month following the end of the period covered. These reports will be on the same project basis as the budget and in similar format to that used in the prior work period. These reports will be supplemented by accompanying reports of cumulative man hours expended, actual to date, by subtask, and for total AEC and total NASA expenditures; and will be further supplemented by separate sets of computer input data in the same format used in the prior work period.

2) Provide narrative comments on significant monthly budget-actual variances by AEC budget and reporting classification on the ninth working day of the month.

3) Submit to AGC separate sets of narrative comments on significant year to date budget-actual variances for the NERVA Program by the 19th calendar day of the month following the report period.

c. Submit reports of Government-owned capital equipment as of September 30, November 30, March 31, and June 30 and of AEC depreciation expense as of September 30, December 31, March 31 and June 30 for the NERVA Program. All the reports are due on the 2lst calendar day following the reporting period except the one for June 30, which is due on the 19th calendar day. 
Project 4200 (Cont.)

d. Submit on the 20th day of December and July, a NASA. form 1018 for each program as required.

e. Submit to AGC on or before the 10th day of each month a report of employment for the preceding month on $\mathrm{AEC}$ form 25l, or equivalent.

(2) Transmit simultaneously to SNPO-C all cost and budgetary information exchanged between the prime contractor and the nuclear subcontractor.

(3) Submit simultaneous Iy to AGC and SNPO-C on the 15th day of every other month, changes made to the approved WANL AEC Capital Equipment lists. Such changes will be accomplished in accordance with AGC letter dated February 8, 1967, Symbol: 7140:3191:SFC:In.

(4) Submit forecasts and utilization reports on pressurants and propellants.

(5) Submit cost estimates for studies and proposals in response to AGC or SNPO requests (guidelines, change notices, requests for proposal) and WANL Sponsor requests. These cost estimates will be prepared on a Project basis for all Projects of the NERVA Nuclear Subsystem Development Program or selected Projects as appropriate. Each proposal cost estimate will include summaries by Agency, and will contain sufficient back-up information to justify the cost estimate. Cost estimates will be submitted simultaneously with proposed program plans.

(6) Communicate to AGC and SNPO the current operating budget for each Project of the NERVA Nuclear Subsystem. This current operating budget will tie in with the total costs, obligations and Agency ceilings stipulated in the contract. Budgets will be submitted 15 days after completion of contract cost negotiations. Format will be as depicted in previous Projected Expenditure Distribution Reports.

(7) Submit on an annual basis cost estimates for Agency Budgets describing operating costs for the NERVA Nuclear Subsystem for the current and next two government fiscal years in a format similar to that used in the prior period. 
Project 4200 (Cont.)

(8) Provide for charging employee layoff income benefit cost as applicable.

(9) Significant variances in a project between an operating budget run and a revised budget run being used for cost comparison purposes shall be explained in writing within seven (7) calendar days following issuance of a revised budget run. Significant variances at the project level are defined as 10\% of the operating budget for the project or $\$ 25,000$, whichever is greater.

B. Fabrication - Not applicable.

C. Testing - Not applicable.

D. Tooling - Not Applicable. 
Subtask 4.3 - Technical Reports

Project 4320- Technical Reports - AEC - Technology

A. Engineering

(1) Progress Reports

a. For each of the first three quarters of Contract Year 1968 prepare a quarterly report covering the technical progress accomplished during the quarter. Each report will be submitted to AGC and SNPO-C by the 25th day of the month following the end of the quarterly period. This report shall include reliability and quality assurance accomplishments.

b. Prepare a technical summary report covering Contract Year 1968 which will be a resume of the year's progress based on the status of the NERVA Program at the beginning of the year and the significant developments accomplished during the year. This report will be submitted to AGC and SNPO-C by the 25th day of October, 1968.

(2) Reactor Design and Test Documentation

Prepare documentation covering, as required, the design and testing of reactors and reactor experiments such as:

a. Reactor Design Criteria Reports

b. Administrative Reports and Documents

c. Fuel Development Reports

a. Test Data Books

e. Final Test Reports

f. Safety Manuals

g. Fuel Element Placement Summary Reports

h. Test Prediction Reports

i. Reliability Manuals

j. Handbooks, Training Aids, and Procedures 


\section{Project 4320 (Cont.)}

(3) Test Facility Design and Operations Documentation

Prepare design manuals and operations manuals, as required, for experimental and reactor test facilities.

(4) Other documentation, as required, will be prepared as follows:

a. Special technical and scientific papers and reports for timely presentation of significant plans and accomplishments.

b. Prepare technical progress and training films.

B. Fabrication - Not applicable.

C. Testing - Not applicable.

D. Tooling - Not applicable. 
Subtask 4.5 - Configuration Management

Project 4509 - Configuration Management Administration - Support

A. Engineering

(1) Develop and implement a Configuration Management Program for the NERVA program consistent with the management and engineering principles delineated in AFSCM 375 series of documents and exhibits.

(2) Prepare and submit for approval one (1) month prior to the conduct of the first PDR a Configuration Management Plan in accordance with the management and engineering principles delineated in the AFSCM 375 series of documents and exhibits. This plan shall be prepared to be consistent with the general format and content prescribed in AFSCM 310 Data Item as follows:

a. C-18-21.0 Configuration Management Plan

(3) Develop, implement, and maintain a system for accomplishing configuration identification, configuration control, and configuration accounting. This system shall utilize the following AFSCM 310 Data Items:

a. C-11-46.0 Specification Maintenance Documents :

1. Specification Change Notice

2. Specification Change Log

3. Specification Identification Index

4. System Configuration Chart

5. End-item Configuration Chart

6. Specification Revisions

b. C-12-35.1 Engineering Change Proposal - System

c. C-13-46.0 Engineering Change Proposal - CEI

d. C-14-46.0 Configuration Management Accounting - Reports 
(4) Prepare and submit a listing of contract data requirements. This listing shall include management, scientific, engineering, and logistics information, reports, documentation and data items which are required for delivery to the Government. This listing shall follow the format of, and contain appropriate information, as delineated in Form DD 1423, which is explained in AFSCM 310, Volume I, Chapter 6, dated 16 January 1967.

(5) Conduct preliminary design reviews of the following:

Nuclear Subsystem CEI

Control Drum Actuator System CEI

SSCV and Actuator System CEI

(6) Establish a configuration control board consistent with the management and engineering principles delineated in the AFSCM 375 series of documents and exhibits.

B. Fabrication - Not applicable.

C. Testing - Not applicable.

D. Tooling - Not applicable. 
Subtask 4.6 - New Technology Reporting

Project 4600 - New Technology Reporting - Technology

A. Engineering

The subcontractor shall perform the following, in accordance with the AEC-NASA Property Rights in Inventions Clause, and additional requirements stipulated below. (To the extent compatible with the level of effort allocated).

(1) Reportable Items: Submit as Reportable Items all inventions, discoveries, improvements, and innovations (including computer programs) made in performance of work under this contract. Prepare Reporiable Items in a manner satisfactory to the AECNASA documentation requirements of both Technology Utilization Representative and Patent Counsel.

(2) Backup Packages: Upon request furnish information (as available) regarding selected Reportable Items. For reportable items that are computer programs provide complete documentation including scientific and mathematical development, source language listing, instructions for use and source card deck or tape.

(3) Supporting Services: The Subcontractor shall provide models, displays, motion pictures, slides, etc., (as available) suitable for portraying the essential working features of selected Reportable Items; assist in the creation of documents, including the engineering, drafting and technical writing support of an order higher than Reportable Items, including Tech Briefs, T.U. Reports, T. U. Notes, T. U. Handbooks, and Technology Surveys; assist in the identification of contractor-originated Reportable Items which have transferred to the civilian economy.

During the performance of subcontracts containing this work statement, the contractor will, upon request by the contracting Officer, (a) provide guidance and limited assistance to the subcontractor in methods of originating, identifying, and submitting Reportable Items; (b) advise of areas of potential or known creativity within the subcontract work which are susceptible to concentrated attention for New Technology Reporting; (c) assist in evaluating the subcontractor's compliance with the word and intent of this work statement.

The subcontractor shall indoctrinate his personnel in the goals of the Technology Utilization Program. Management involved shall include a promotion of the awareness of the program using displays, bulletin boards, articles in the house organ and other advertising media. An incentive program including monetary awards to individuals for merited disclosures, and recognition of these individuals in publications shall be continued by the subcontractor. 
Project 4600 (Cont.)

The subcontractor will upon request provide preliminary adaptive engineering and market surveys on selected reportable items.

(4) Special Activities: Participate in NASA/AEC sponsored New Technology seminars and conferences, as required.

(5) Reporting

a. Standard: Submit Formal Quarterly Report as part of the Quarterly NERVA Progress Report.

b. Special: Identify and document, (l) major scientific and engineering advances in the state-of-the-art resulting directly from the contractor's participating in the AEC-NASA Nuclear Rocket Program; (2) new company skills, of possible civilian economy interest, developed under the program; (3) new vendor products and processing resulting from the program; (4) contractor use of ideas contained in Tech Briefs and associated documents.

c. None of the foregoing shall be construed as requiring subcontractors to submit Reportable Items via the prime contractor.

B. Fabrication - Not applicable.

C. Testing - Not applicable.

D. Tooling - Not applicable. 
Subtask 6.0 - Capital Equipment WANL, Pittsburgh

Project 6009 - AEC Capital Equipment - WANL, Pittsburgh - Support

A. Engineering - Not applicable.

B. Fabrication

(1) Procure and install AEC equipment to the extent of the available funding in agreement with the NERVA Nuclear Subsystem AEC Capital Equipment plan and as revised in accordance with programmatic requirements and budgetary constraints for the following projects:

a. 2809 Non-Fuel Material Planning, Design Review and Data Reporting - Support

b. 8041 Mechanical Development Tests - Reactor

c. 8071 Corrosion and Flow Development Testing - Reactor

d. 8091 Reactor Proof Critical Testing - Reactor

e. 8190 Reactor Assembly and Shipping - Technology

f. 8901 Fuel Element Process - Reactor

g. 8921 Fuel Element Materials Development - Reactor

h. Other Projects as Required.

C. Testing - Not applicable.

D. Tooling - Not applicable. 
Subtask 6.0 - Capital Equipment - WANL, Pittsburgh

Project 6019 - NASA Plant Equipment - WANL, Pittsburgh - Support

A. Engineering - Not applicable.

B. Fabrication

(1) Procure and install Capital Equipment to the extent of the available funding for the following NASA funded projects:

a. 1500 Control System Design and Analysis - Technology

b. 1989 Radiation Effects - Testing Equipment Support

c. Other Projects as Required.

C. Testing - Not applicable.

D. Tooling - Not applicable. 
Subtask 6.1 - Capital Equipment - NRDS

Project 6109 - AEC Capital Equipment - NRDS - Support

A. Engineering - Not applicable.

B. Fabrication

(1) Procure and install AEC equipment to the extent of the available funding at NRDS in agreement with the NERVA Nuclear Subsystem AEC Capital Equipment plan and as revised in accordance with programmatic requirements and budgetary constraints for the following projects:

a. 2100 Mechanical Ground Support Equipment - Technology

b. 2200 Electrical Ground Support Equipment - Technology

c. Other Projects as Required.

C. Testing - Not applicable.

D. Tooling - Not applicable. 
Subtask 7.0 - NRDS Operations

Project 7017 - General Support - NRDS

As part of NTO assist in performing the following functions:

A. Activation - Not applicable

B. Operations

Provide the necessary administrative, engineering, planning and training personnel to support the following NERVA activities at NRDS:

(1) Management of NERVA Test Operations (NTO).

(2) Program planning to support test operation activities and facility activation programs in accordance with the $\mathrm{NRX}$ and $\mathrm{XE}$ test program requirements.

a. Direct the overall planning and scheduling of all NTO activities at the Nuclear Rocket Development Station (NRDS).

b. Prepare, issue, and maintain current the Program Requirements Document (PRD) in accordance with mutually agreeable milestones.

c. Provide liaison with othen program participants.

(3) Continue the NERVA training program to provide specialized indoctrination and familiarization to, and qualification of, the appropriate operating personnel to meet NRX and XE program requirements. The effort shall include; the executing and/or coordinating of training objectives, standards and qualification criteria; preparing and maintaining training material (texts, audio and visual aids, etc.); administering course presentations and examinations; training instructors, and maintaining training records.

(4) Provide design engineering and analysis efforts as required to support the testing objectives of the NERVA Program.

(5) Prepare and maintain Standard operating and Administrative Procedures and Instructions for NTO. Publish and maintain Technical Procedures and Specifications for NRX and XE test articles. Edit and publish Technical Reports, including eight-hour, three-day and final data reports, for the NRX and $\mathrm{XE}$ testing. 
(6) Provide a work order coordinator to issue and control work order packages through SNPO-N for implementation.

(7) Review and provide analyses for facility ECR's, provide consulting services to all operating groups, and provide the NTO engineering liaison with source engi neering.

(8) Support site efforts in the monitoring of fission product release.

(9) Provide the technical management and engineering to administer configuration control.

(10) Provide engineering support for Test Cell "C" operations.

(11) Perform nuclear power calibration of all reactors and engines.

(12) Assist in the definition of test specification required dosimetry and define the facility required dosimetry. Accomplish the design, procurement, placement, analyses and data reporting of all dosimetry for the reactor and engine test series. Assist IASL in the dosimetry program for Test Cell "C". 
Subtask 7.1 - Test Cell "C" Operations and Modifications

Project 7107 - Test Cell "C" Operations and Modifications - NRDS

A. Activation - Not applicable.

B. Operations

(1) As a part of the joint LASL/NTO Test Cell "C" organization, participate in the operations of the Test Cell " $C$ " facility for IRX-A6, PHOEBUS test series, and PEWEE testing. Assist IASL for CY 1968 in the operation of Test Cell "C" facilities. Maintain capability in the following areas:

a. Analyze data from facility checkout tests, PHOEBUS reactor tests, and $\mathrm{PEWEE}$ reactor tests, to identify modifications required and to assure that Test Cell " $\mathrm{C} "$ is prepared for future NERVA reactor testing.

b. Provide electrical and mechanical engineering support for the design of system and facility modifications required for PHOEBUS, NRX-A6 and PEWEE reactor testing.

c. Assist in the preparation of documents defining operations support required for reactor testing and other procedures required by the Test Documentation.

d. Coordinate the assigning of personnel and space, establishing schedules and the maintenance and modifications of Test Cell "C".

e. Provide test operations personnel to conduct facility, PHOEBUS, NRX-A6 and PEWEE testing.

f. Coordinate with other program participants all activities associated with PHOEBUS and NRX-A6 test operations, sideby-side experiments and information transmittal in Test Cell "C".

g. Coordinate and provide design requirements, analysis, specifications and detailed design of the control and data systems and modifications thereto, as required for the functional, operational and safety adequacy at Test Cell "C".

h. Perform evaluation of Test Cell " $\mathrm{C}$ " control system adaptability to accommodate the NRX-A6, PHOEBUS, PEWEE and future NERVA reactors as specified by the applicable test documentation. 
Project 7107 (Cont.)

i. Formulate test plans for Test Cell "C" facility checkouts required prior to each PHOEBUS and PEWEE test series and prepare functional requirements for the facility test car or facility bypass plumbing.

j. Determine Test Cell "C" tank farm assignments, relief valve settings, control points, etc., for the reactor tests.

k. Provide system descriptions for necessary Test Cell " $C$ " mechanical, electrical and electronic systems.

(2) Perform failure mode and safety analyses on the mechanical, electrical, and electronic systems, including any changes to the systems.

(3) Perform engineering and operations in support of the data acquisition and reduction systems.

(4) Provide supervision of support services contractor personnel in their conduct of maintenance and operation of Test Cell " $C$ " facility systems, including R-CP.

(5) Coordinate and document the training of personnel. 
Subtask $7 \cdot 3$ - Mad Building Operations

\section{Project 7317 - Reactor Operation - NRDS}

As part of NTO assist in performing the following functions:

A. Activation - Not applicable.

B. Operations

Provide management, engineering, and technician support for NRX-A6 assembly, disassembly and post-mortem operations in accordance with the NERVA Program PIan and for support to IASL for PHOEBUS related operations.

(1) Provide support to the IASL/PHOEBUS program for the assembly, transport, disassembly, post-operative examination and radiochemistry of PHOEBUS test articles at the R-MAD facility, for the KIVA assemblies at Ios Alamos, New Mexico, and for the monitoring of fission product release at NRDS.

(2) Complete the NRX-A6 assembly, disassembly, post-operative examination, radio-chemistry, and related operations at the E-MAD and R-MAD facilities as required by the test specification. Prepare the procedures and the required SOP's for these operations.

(3) Provide facility and equipment interface specifications for special handling equipment and tooling.

(4) Complete the transfer of NERVA equipment from R-MAD to E-MAD, consistent with program requirements.

(5) Provide minor jigs and fixtures required in support of NRX operations, including field modifications to special handling equipment.

(6) Provide assistance and support as required for the planning and preparation for the moth-balling of the R-MAD facility. 
Subtask $7 \cdot 3$ - MAD Building Operations

Project 7327 - Engine Operations - NRDS

As part of NTO assist in performing the following functions:

A. Activation - Not applicable.

B. Operations

Provide management, engineering and technician support and materials and equipment as required to perform assembly, transport, integration, and checkout of the test article assemblies; recover, maintain, disassemble and perform the post-mortem examination of the test hardware in accordance with the NERVA Program Plan.

(1) Provide direction, supervision, and/or liaison with the support Services Contractors (SSC).

(2) Prepare the assembly, disassembly, transport, post-operative and maintenance procedures and the required $S O P^{\prime} S$ for $X E C F, X E-I$ and XE-2.

(3) Coordinate the E-MAD with the ETS-1 operations and perform engine transport, installation, checkout in-stand, and recovery from stand for returm to the E-MAD facility.

(4) Complete the assembly, checkout, transport and test stand integration of the $\mathrm{XE}-1$ test article, complete the disassembly of the XECF, and complete the assembly of XE-2.

(5) Provide minor jigs, fixtures, and special test equipment as required for hot and cold area setups.

(6) Provide facility and equipment interface specifications for special handling equipment and tooling.

(7) Operate and maintain the Railroad Transport System Equipment in support of NERVA and PHOEBUS test article operations and Radioactive Materials Storage Facility (RMSF) operations.

(8) Provide the engineering and technical support as required to perform a remote (cold) XECF UTSM interchange demonstration and a remote (hot) XE-I/XECF UTSM interchange demonstration.

(9) Direct the maintenance, repair, and modification to the E-MAD facility systems and equipment as required.

(10) Complete activation in the Core Disassembly and Examination (CDAE) area to support the $\mathrm{XE}-1$ and subsequent test article operations.

(11) Provide the technical management and engineering to administer configuration control for E-MAD. 
Project 7327 (Cont.)

(12) Perform system integrated operations employing mockups, NERVA hardware and specialized handling and transport equipment.

(13) Continue the development and qualification of operating and maintenance personnel. 
Subtask 7.4 - ETS-1 Operations

Project 7407 - Engine Test Operations - NRDS

As part of NIO assist in performing the following functions:

A. Activation

Provide the necessary engineering and facility management functions to permit $\mathrm{XF}-1$ to be installed and tested in ETS-I in accordance with the XE Program Plan.

\section{B. Operations}

(1) Provide the engineering and facility management functions for the modification, checkout, operation and maintenance of the ETS-I facility as required by the XE Program Plan.

(2) Provide the supervision of and requirements for support Contractor's personnel during the checkout and maintenance of the ETS-I facility and the conduct of XE tests and subsequent operations.

(3) Provide the technical management and engineering to administer ETS-1 configuration control.

(4) Provide operational analysis of the ETS-I facility to assess the integrated facility operational, functional, and safety characteristics and to develop guidelines for operational planning.

(5) Provide test planning and prepare Test Descriptions, Test Operating Procedures, Support Operational Requirement Documents, Test Reports, and other documents required in support of the Test Program.

(6) Review and analyze test data to assure that the facility conforms to the $\mathrm{XE}$ test requirements.

(7) Provide the point of official liaison with all other program participants for all activities associated with XE operations at NTO.

(8) Provide and maintain the necessary channel engineering, data processing, and computer programs required for the facility systems and test article operations.

(9) Review and provide input to the XE Test Specifications, SAR, SER, and other externally generated documents related to the XE Test Program at ETS-1.

(10) Assist in the review and analyzing of XE test data to assure compliance with the test requirements. 


\section{Project 7407 (Cont.)}

(II) Coordinate and review engine/facility modifications for functional, operational, and safety adequacy at ETS-l.

(12) Investigate and coordinate the nuclear activities associated with the XE Test Program, including decontamination of the test stand and surrounding areas.

(13) Conduct the XECF and XE-I Test Programs in accordance with the applicable Test Specification and other controlling Test Documentation. 
Subtask 7.7 - NRDS and Advanced Facilities Support

Project 7710 - Engineering Support - Existing NRDS Facilities - AEC - Technology

\section{A. Engineering}

(1) Evaluate the capabilities of Test Cell "C" and ETS-I test facility systems to support the $\mathrm{NRX}-\mathrm{A} 6$, and the $\mathrm{XECF}, \mathrm{XE}-1$ and $\mathrm{XE}-2$ test objectives.

(2) Evaluate the capabilities of ETS-I test facility systems to maintain the $X \mathrm{XF}-1$ and $\mathrm{XE}-2$ nuclear subsystem restartable in the event of single credible facility test system malfunctions.

(3) Define ETS-I facility tests to provide data for evaluation of test facility performance for XECF, XE-1 and XE-2.

(4) Recommend Test Cell "C" and ETS-l facility design changes of modifications determined to be required from the facility performance evaluations for WANL requirements for NRX-A6, XECF, $\mathrm{XE}-1$ and $\mathrm{XE}-2$.

(5) Assist in maintaining Test Cell "C" and ETS-I test facilities in proper status to support the WANL requirements for XECF, $X E-1$ and $X E-2$ tests by participation in configuration control of the facilities.

(6) Assist in the development of analog and digital models representing the Test Cell " $\mathrm{C}$ " by providing engineering data and by review of the models.

(7) Assist in defining analog and analyses to be performed and evaluate their results along with Test CelI "C" and ETS-I test data to evaluate their test systems performance.

(8) Provide support for input to and review of Measurements Requirements Lists.

(9) Provide services to act as chairman of and representative to the WANL Instrumentation Committee.

(10) Provide engineering support in the implementation and analysis of AC-coupled and zero suppressed data requirements for NRX-A6, $X E C F, X E-1$ and $X E-2$.

(11) Conduct instrumentation systems engineering and analysis and provide support in the evaluation of overall reactor-related instrumentation systems performance in Test Cell "C" and ETS-I.

(12) Provide Functional Requirements and Design Criteria for Additions or Modifications to the data Acquisition System at Test Cell "C" and ETS-I, pertaining to reactor oriented instrumentation to assure that the systems will meet the test objectives. Review proposed modifications as required to assure these meet criteria and requirements. 
Project 7710 (Cont.)

B. Fabrication - Not applicable.

C. Testing - Not applicable.

D. Tooling - Not applicable. 
Subtask 7.7 - MRDS and Advanced Facilities Support

Project 7769 - Engineering Support for Existing IRDS Facilities - NASA - Support

A. Engineering

(1) Provide support to AGC in the preparation and maintenance of the ETS-I Facility CEI Specification - Part I in accordance with the management and engineering principles delineated in the AFSCM 375 series of documents and exhibits.

B. Fabrication - Not applicable.

C. Testing - Not applicable.

D. Tooling - Not applicable. 
Project 7809 - E/STS 2/3 Facility Support

A. Engineering

(1) Provide representation on the E/STS 2/3 Task Force through November 1967.

(2) Provide "in-plant" support of E/STS 2/3 design requirements, as required through November 1967.

(3) Provide E/STS $2 / 3$ activation planning, as required, to aid in the design E/STS $2 / 3$ through November 1967.

(4) Provide nuclear safety, instmmentation, and control support to the E/STS 2/3 Task Force, as required through November 1967.

(5) Assist in preparation of final E/STS 2/3 Task Force reports and other documentation.

B. Fabrication - Not applicable.

C. Testing - Not applicable.

D. Tooling - Not applicable. 
Subtask 8.0 - Nuclear Subsystem Development

Project 8000 - Reactor Design, Development and Follow-up - Technology

\section{A. Engineering}

(1) Define fuel element requirements and configurations for the NERVA Technology Program. Review and approve fuel process specifications. Release fuel element drawings for fabrication. Provide design guidance for the fuel element manufacturing and the component test program.

(2) Provide design and instrumentation layouts and detail drawings to define the $\mathrm{XE}-2$ reactor, adhering as closely as possible to $\mathrm{XE}-1$. Complete the release of detail and assembly drawings for $\mathrm{XE}-2$ reactor. Incorporate the requirements of Product Assurance, Materials, Manufacturing Engineering and Reactor Analysis.

(3) Provide instrumentation installation layout and detail drawings incorporating the requirements and installation design with Instrumentation and Controls, Test Engineering and Reactor Analysis. Update the instrumentation requirements for $\mathrm{XE}-2$ reactor.

(4) Evaluate differences between $X E-1$ and $X E-2$ run profiles and effect on stresses and issue report, if required.

(5) Provide design guidance for the component test program. Coordinate test description, test plans, test setups, procedures and results to insure that design requirements are achieved.

(6) Review design, component development and analysis with SNPO-C, Los Alamos Scientific Laboratory, and Aerojet-General on a continuing basis. Maintain liaison with Aerojet-General and SNPO-C relative to $X E-1$ and $X E-2$ engine systems test and the effect on design requirements. Incorporate changes into the design stress analysis and developmental test program as determined from engine tests.

(7) Establish reactor, pressure vessel, and nozzle interface requirements in cooperation with $\mathrm{AGC}$ and coordinate all revisions and deviations through the interface control system.

(8) Prepare and maintain a List of Parts to define the engineering parts requirements for the $\mathrm{XE}-2$ reactor.

(9) Evaluate drawing changes proposed by vendors and WANL groups. Prepare and process engineering change orders as required to release and revise the detailed and a'ssembly drawings in accordance with the latest technical requirements. 
Project 8000 (Cont.)

(10) Evaluate discrepant parts reported by vendors and Receiving Inspection, and establish disposition of the subject parts.

(11) Provide input, review, and approve reactor assembly procedures on a continuing basis.

(12) Provide the necessary engineering assistance during XE-2 assembly operations.

(13) Define the mechanical design data and accuracy requirements for the XE-2 specifications.

(14) Review and comment on Test Plans, Test Specifications and NTO procedures for $\mathrm{XE}-1$ and $\mathrm{XE}-2$ to ensure that the design requirements are fulfilled.

(15) Specify stress, deflection and acceleration "red line" limits for the XE-2 tests.

(16) Provide engineering coverage for $\mathrm{XECF}, \mathrm{XE}-1, \mathrm{XE}-2$ and NRX-A6 during the installation, testing and disassembly operations at NRDS and for completion of post-operative examination of $\mathrm{NRX}-\mathrm{A} 6$ and $\mathrm{XE}-1$.

(17) Analyze the significance of data obtained from component and reactor testing. Issue $\mathrm{NRX}-\mathrm{A} 6$ post-operation data analysis and mechanical component evaluation reports.

B. Fabrication - Not applicable.

C. Testing - Not applicable.

D. Tooling - Not applicable. 
Subtask 8.0 - Nuclear Subsystem Development

\section{Project 8001 - Reactor Design, Development and Follow-up - Reactor}

\section{A. Engineering}

(1) Provide design and instrumentation including structural analysis layouts to define the $\mathrm{R}-1$ incorporating input from Product Assurance, Materials, Manufacturing Engineering and Reactor Analysis. Review drawings for methods of reducing hardware costs and minimizing manufacturing discrepancies.

(2) Conduct developmental studies including structural analysis and prepare study layouts for specific components based on the results of component and reactor testing and analysis and prime equipment specification requirements. These study layouts include :

a. Ganged drive mechanism for control drums.

b. Design of reactor axial support system.

c. Cluster axial support.

d. Improved means of corrosion protection of core components.

e. Design of a shadow shield and internal crew shield if required in the specification.

f. Poison wires for the anti-criticality poison system.

g. Core periphery.

(3) Review the technical requirements of the reactor design assembly, test, disassembIy, and post-test evaluation with other WANL departments, NTO, AGC, IASI, and SNPO.

(4) Prepare instrumentation installation layouts incorporating requirements of Instrumentation and Controls, Test Engineering, Structural Analysis and Reactor Analysis.

(5) Specify need for development tests and continually review test programs with Engineering Mechanics and Thermo-Flow Laboratory to reflect latest designs. Pending application of the Configuration Management System, an agreed upon method of informally communicating the content of the scope of test documents to AGC and SNPO-C will be implemented. Review test plans, test setups, procedures and results to insure that design and analysis requirements are achieved. Prepare layout and detail drawings for development test components and release for procurement. Follow development testing and integrate results into design.

(6) Perform preliminary and conceptual stress and vibration analysis on the nuclear subsystem internal to the pressure vessel. 
(7) Define fuel element requirements and configuration. Review and approve fuel process specifications in support of the fuel development program. Release fuel element drawings for fabrication in support of the fuel development program. Perform stress analysis of fuel elements and related hardware for steady state and transient conditions. Provide design guidance for the fuel element manufacturing and component test program.

(8) Review design structural analysis and component development program with SNPO-C, IASI, and AGC on a continuing basis.

(9) Establish reactor, pressure vessel, and nozzle interface requirements in cooperation with $A G C$ and process all revisions and deviations through the Interface Control System.

(10) Review and approve new and revised materials and process specifications for the $R-1$ reactor.

(11) Release long lead R-I material designs for procurement.

(12) Support the preparation of the AFSCM 310 data items specified in Project 1172 and the NERVA Engine CEI Specification - Part I as appropriate.

(13) Based on Reactor Reliability Requirements and Failure Mode Analysis, incorporate design redundancy into the more critical components and where not feasible, conduct alternate component design studies to ensure the required overall reactor reliability.

(14) Perform the steady-state and transient stress analyses and dynamic analyses of the "prime" configuration in accordance with the requirements of the structural design specification SNPO-C-I, Revision O, as modified by AGC/WANL/SNPO-C agreements, or in agreement with approved procedures in the NERVA Configuration Management Manual.

(15) Conduct detailed vibration analyses to determine the natural frequencies of major reactor components. Prepare an analytical. model of the reactor system in terms of series and parallel combinations of mass - springs - dampers. Coordinate the investigation of the overall flow system within the reactor to identify any possible problems due to resonance with major components. Initiate studies to evaluate the dynamic response of reactor components and assemblies to the shipping and test environments. Specify any design modification required to ensure against flow induced vibrations.

(16) Support parametric shield studies relative to materials feasibility and shield location. 
Project 8001 (Cont.)

(17) The Structural Analysis group shall approve all structural drawings prior to their release in accordance with the Structural Design, Specifications, SNPO-C-I, Revision O, as modified by AGC/WANL/SNPO-C agreements.

(18) Investigate alternate means of cluster support.

a. Perform design studies of alternate cluster support methods. Prepare study layouts of various configuration. Select and release designs for development testing.

b. Perform stress analysis of the selected alternate configurations. Compare results with the pedestal design.

c. Define component testing requirements for the selected configurations.

d. Prepare comparative study of brazed versus forged support stems.

B. Fabrication

Provide models and mockups of reactor components and assemblies to assist in design evaluation and instrumentation installation.

C. Testing - Not applicable.

D. Tooling - Not applicable. 
Subtask 8.0 - Nuclear Subsystem Development

Project 8010 - Thermal and Fluid Flow Design - Technology

\section{A. Engineering}

(1) Complete orifice specification ( $E P O D$ ) for $\mathrm{XE}-2$ reactor.

(2) Perform the analysis of reactor hot channel factors for XE-2 on the basis of inspection data from the fuel manufacturing operation and laboratory test, and determine statistically the effect of these data on reactor performance.

(3) Perform the corrosion analysis for XE-2.

(4) Perform the final analytical determination of the temperature patterns and fluid loads on key components of the XE-2 reactor and replacement shield.

(5) Perform XECF test analysis to evaluate effects of XE-I startup on Nuclear Sub-System (NSS).

(6) Complete supplements to NRX-A6 Test Predictions Report.

(7) Complete XE-I NSS quick-look prediction analysis and support malfunction analysis on XE-I NSS.

(8) Complete the thermal and fluid flow analysis for NRX-A6 power test data and initiate the analysis of XE-I power test NSS data.

(9) Complete the corrosion analysis of the power test and the comparisons with disassembly measurement for NRX-A6 and initiate on $\mathrm{XE}-1$ reactor.

(10) Complete the prediction of the corrosion, thermal, and fluid flow quick-look data for the XE-2 over the complete test profile including cooldown analysis.

(II) Continue development of reactor test data handling programs for $N R X-A 6$, $X E-1$, and $X E-2$ reactors.

(12) Provide support to Nuclear Safety Analysis in hazards analysis, Control Development in instrment heating analysis, and digital check of analog models and to Test Engineering in test specification data.

(13) Provide coordination with AGC of fluid flow interfaces.

(14) Support the Data Review Team, Test Diagnostic Console, Data Handling, DRAGON and SPEAR Teams for NRX-A6, XECF, XE-I, and the disassembly operations for $\mathrm{XE}-1$ and $\mathrm{NRX}-\mathrm{A} 6$. 
Project 8010 (Cont.)

(15) Complete analysis required to evaluate the manufacturing variation requests for $\mathrm{XE}-2$ reactor.

B. Fabrication - Not applicable.

C. Testing - Not applicable.

D. Tooling - Not applicable. 
Subtask 8.0 - Nuclear Subsystem Development

Project 8011 - Thermal and Fluid Flow Design - Reactor

A. Engineering

(1) Perform thermal, fluid flow, and corrosion parametric analyses to support the Nuclear Subsystem size selection and establish gross performance capability.

(2) Perform thermal, fluid flow, and corrosion analysis of reactor and reactor components to define the conceptual design of the Nuclear Subsystem.

(3) Perform thermal, fluid flow, and corrosion preliminary analysis to support the Nuclear Subsystem design and long lead material release program commitments.

(4) Perform thermal, fluid flow, and corrosion intermediate analyses to support component hardware release program commitments.

(5) Define the component test program and prepare component test requests, predict test results, monitor tests and perform posttest analysis to verify the thermal, fluid flow and corrosion characteristics and capabilities of the Nuclear subsystem. Analyze and assess design significance of the test results.

(6) Conduct thermal, fluid flow, and corrosion analyses of hardware changes to the Nuclear Subsystem design required by NRX-A6 post-test evaluation, preliminary or intermediate initial analyses, and by initial component tests.

(7) Perform the thermal fluid flow, and corrosion analysis required to support reflector structure and lateral support and seal system development, composite cluster supports, ganged control drum drive system development, cluster axial support system development, flight-type shield development, and anticriticality poison system development.

(8) Define the thermal, fluid flow, and corrosion inputs for fuel element development specifications for the Nuclear Subsystem.

(9) Define the preliminary thermal, fluid flow, and corrosion characteristics of the Nuclear Subsystem over the range of operation required by the PFRT rating under both steady-state and transient conditions. This analysis is to demonstrate that the reactor will meet PFRT rating requirements.

(10) Perform thermal and corrosion analyses required to define fuel element environment in electrical testing and its relationship to reactor environment, and to develop corrosion understanding leading to reactor design and lifetime considerations. 
Project 8011 (Cont.)

(11) Develop improved analytical models for prediction of performance characteristics, fluid flow, thermal, and corrosion characteristics of the Nuclear subsystem as required to support above work utilizing heat transfer, fluid flow, and corrosion test data.

(12) Provide the necessary input to maintain the AGC fluid flow interfaces.

(13) Provide support to accident analysis, malfunction analysis, dynamic analysis, instrument heating analysis, and digital check at analog models.

(14) Define reactor internal measurement list (RIM) for instrument requirements for the $\mathrm{R}-1$ Reactor.

(15) Thermal analysis of the reactor thermal and pressure environment in space to support the materials development program.

(16) Support the preparation of the AFSCM 310 Data Items specified in Project 1112 and the NERVA Engine CEI Specification - Part I, as appropriate.

(17) Investigate alternate means of cluster support by conducting thermal and flow analyses of selected alternate support configurations. Compare results with the pedestal design. Provide material temperature input to structural analysis group. Define fluid flow tests required to substantiate the adequacy of the candidate designs.

B. Fabrication - Not applicable.

C. Testing - Not applicable.

D. Tooling - Not applicable. 
Subtask 8.0 - Nuclear Subsystem Development

Project 8020 - Reactor Nuclear Design - Technology

\section{A. Engineering}

(1) Complete analyses to determine the nuclear characteristics of the final design of the $\mathrm{XE}-2$ reactor.

(2) Complete the test requests, predictions, and analysis of critical experiments in support of the $\mathrm{XE}-2$ reactor.

(3) Perform analyses to determine the nuclear effects of mandatory hardware changes to the XE-2 design.

(4) Specify the assembly and shipping poison for the XE-2 reactor.

(5) Perform analyses to determine the power factors used in developing orifice specifications for the XE-2 reactor.

(6) Specify the reactivity shim content for the $\mathrm{XE}-2$ reactor based upon manufacturing inspection data and critical experiments.

(7) Conduct the nuclear analyses required to evaluate the manufacturing variation requests for the $\mathrm{XE}-2$ reactor.

(8) Review instrumentation requirements and test procedures for the XE-2 power test.

(9) Update reactivity coefficients and other kinetic parameters necessary for control and accident analysis of the XE-2 reactor.

(10) Provide nuclear analysis support to reactor safety analysis and reactor assembly.

(11) Perform predictions of the nuclear behavior of the XE-2 reactor over the complete test profile, and finalize predictions for XE-I.

(12) Support Data Review Team, Test Diagnostic Console, DRAGON, and SPEAR Team, and disassembly operations for the NRX-A6 and XE-1 reactors.

(13) Perform post-test analysis of the NRX-A6 and XE-I power test data; prepare input to NRX-A6 final test report and initiate preparation of input to $\mathrm{XE}-1$ final test report.

B. Fabrication - Not applicable.

C. Testing - Not applicable.

D. Tooling - Not applicable. 
Subtask 8.0 - Nuclear Subsystem Development

Project 8021 - Reactor Nuclear Design - Reactor

\section{A. Engineering}

(1) Perform nuclear parametric and conceptual design studies to support the establishment of the size of Nuclear Subsystem.

(2) Perform preliminary nuclear design studies to support longlead material release for $\mathrm{R}-1$.

(3) Initiate detailed nuclear analyses to support hardware release for R-I and provide input for fuel element development specification for the NSS development effort.

(4) Perform nuclear studies adequate to support the determination of shielding criteria for man-rating and engine clustering.

(5) Define preliminary nuclear characteristics of the Nuclear Subsystem over the operating map, under steady-state and transient conditions.

(6) Prepare the test requests, predictions, and analysis of the FCX and/or modified PAX experiments in support of $\mathrm{R}-1$.

(7) Perform analyses to determine the nuclear effects of hardware changes to the Nuclear subsystem design required on the basis of power tests, component tests, or critical experiments.

(8) Initiate analysis to specify the assembly and shipping poison systems for the $R-I$ reactor.

(9) Specify preliminary instrumentation requirements for the $R-1$ power test.

(10) Specify preliminary reactivity coefficients and other kinetic parameters necessary for control and accident analysis of the Nuclear Subsystem.

(11) Provide nuclear analysis support to reactor safety and failure mode analysis.

(12) Prepare the test requests, predictions and analysis of basic flexible critical experiments (FCX) in support of methods development for NERVA reactors.

(13) Continue limited program of improving analytical method for predictions of nuclear characteristics as required to support this Project using available critical experiments and power test data, including PHOFBUS data. 


\section{Project 8021 (Cont.)}

(14) Support the preparation of the AFSCM 310 data items specified in Project 1112 and the NERVA Engine CEI Specification - Part 1 as appropriate.

B. Fabrication - Not applicable.

C. Testing - Not applicable.

D. Tooling - Not applicable. 
Subtask 8.0 - Nuclear Subsystem Development

Project 8030 - Shielding and Radiation Analyses - Technology

\section{A. Engineering}

(1) Complete analysis of the effect on radiation characteristics due to hardware changes to the XE-2 required by design modifications.

(2) Perform the radiation analysis required to provide radiation heating, neutron flux, and gamma ray dose distributions internal and external to the XE-2.

(3) Evaluate the effect of the ETS-I facility shielding on the radiation environment of the nuclear subsystem for $\mathrm{XE}-2$.

(4) Prepare test requests, predictions, and analysis of PAX experiments performed in support of XE-2.

(5) Prepare test requests for special measurements during power testing of $\mathrm{XE}-2$.

(6) Initiate the predictions of the radiation quick-look data for $\mathrm{XE}-2$.

(7) Provide facility shielding, control detector, and activation analysis support in Test Cell "C", and control detector support in ETS-1.

(8) Perform analysis of the power test dosimetry from NRX-A6 and $X E-1$.

(9) Provide input to the AGC/WANL common radiation analysis model for $\mathrm{XE}-2$.

B. Fabrication - Not applicable.

C. Testing - Not applicable.

D. Tooling - Not applicable. 
Subtask 8.0 - Nuclear Subsystem Development

Project 8031 - Shielding and Radiation Analyses - Reactor

\section{A. Engineering}

(1) Complete conceptual design and preliminary design analysis of the radiation heating, neutron flux and gamma dose distributions internal and extermal to the Nuclear Subsystem to support longlead material release.

(2) Perform parametric radiation design analyses of the Nuclear subsystem flight shield to meet the specified shield criteria.

(3) Perform scoping parametric radiation analyses using one and two dimensional geometries and source strength analytical models as required to define the attenuation and size requirements for internal forward shielding and for internal side shielding for man-rated and clustered module operation.

(4) Initiate evaluation of the effect of Test Cell "C" on the radiation environment of the $R-I$ nuclear subsystem.

(5) Prepare test requests, predictions and analysis of critical facility experiments performed in support of shield development for the Nuclear subsystem.

(6) Prepare test requests, predictions and analysis of critical facility experiments performed in support of radiation analysis of the Nuclear Subsystem.

(7) Perform analysis of changes in Nuclear Subsystem radiation characteristics due to reactor and shield hardware changes required by design modifications.

(8) Prepare preliminary requirements for special measurements during power testing of the $\mathrm{R}-\mathrm{I}$.

(9) Provide facility shielding and activation analysis support for $\mathrm{R}-1$ testing in Test Cell "C".

(10) Provide control and safety instrumentation development and analysis support for $\mathrm{R}-1$ testing in Test Cell "C".

(11) Continue limited program of improvements to analytical methods for prediction of radiation characteristics to support this Project utilizing critical experiment and power test dosimetry data, including PHOEBUS data, and basic physics data where necessary.

(12) Provide input to the WANL-AGC common radiation analysis model for Nuclear Subsystem. 
Project 8031 - (Cont.)

(13) Provide support to safety, reliability, and failure mode analysis.

(14) Support the preparation of the AFSCM 310 data items specified in Project 1112 and the NERVA Engine CEI Specification - Part I as appropriate.

(15) Conduct additional FASTER Monte Carlo analyses of the $5000 \mathrm{Mw}$ reactor die system required in order to determine the fraction of radiation leakage from the side of the reactor to the crew location.

(16) Conduct radial one-dimensional $S_{n} T A P A T$ analyses required to extend $\mathrm{R}-1$ side shield studies from 40 to $120 \mathrm{gm} / \mathrm{cm}^{2}$ thicknesses.

(17) Conduct KAP V point kermel analyses of the effect of relocating the vehicle shield material on extermal environment necessary since the results of the "streaming" calculations are in question.

B. Fabrication - Not applicable.

C. Testing - Not applicable.

D. Tooling - Not applicable. 


\section{Subtask 8.0 - Nuclear Subsystem Engineering}

Project 8040 - Mechanical Development Test - Technology

\section{A. Engineering}

(1) Develop methods and procedures for conducting tests in support of the XECF resonant survey.

(2) Conduct resonant survey tests in line with pre-established specific parameters.

(3) Evaluate test results and subinit data, conclusions and recommendations for use in subsequent designs and/or establishing engine test conditions.

(4) Prepare written reports based on the tests conducted.

(5) Design test fixtures and instrumentation necessary to conduct required tests.

(6) Issue documents describing experimental plans as they develop.

B. Fabrication

(1) Fabricate fixtures and instrumentation necessary to perform the required tests.

(2) Provide for associated test hardware such as accelerometers, cables and recording devices.

C. Testing

(1) Perform tests to provide experimental data to determine system vibration characteristics prior to $\mathrm{XE}-1$ testing and to corroborate analyses which have been completed.

D. Tooling - Not applicable. 
Subtask 8.0 - Nuclear Subsystem Engineering

Project 8041 - Mechanical Development Tests - Reactor

A. Engineering

(1) Establish plans for the pre-qualification and qualification test program for the Nuclear Subsystem.

(2) Develop methods and procedures for conducting planned tests.

(3) Evaluate test results and submit data, conclusions and recommendations for use in subsequent designs.

(4) Prepare written reports based upon the tests conducted.

(5) Design all test fixtures, rigs, and systems necessary to conduct planned tests.

(6) Issue documents describing experimental plans as they develop.

(7) Support the preparation of the AFSCM 310 Data Items specified in Project 1112 and the NERVA Engine CEI Specification - Part 1, as appropriate.

B. Fabrication

(1) Fabricate all rigs, fixtures, and systems necessary to perform the required tests.

(2) Provide for non-fuel mechanical test hardware.

C. Testing

(1) Conduct tests in the following areas to provide developmental information that will aid in extending the reactor operating capability consistent with overall programmatic planning:

a. Establish the suitability of the manufacturing techniques to be used for the support stem and provide test data on the mechanical performance of design variations.

b. Determine the strength of reactor core components at anticipated engine temperatures, specifically fuel element and cluster components.

c. Evaluate the ability of core components to withstand the anticipated thermal cycles, thermal gradients and thermal shock which will be experienced by the core. The effects of these tests on the integrity and adherence of coating will also be performed. 
Project 8041 (Cont.)

d. Test candidate core periphery designs under simulated reactor conditions to evaluate the overall performance and provide development data to improve the design.

e. Modify and utilize the existing partial length core to perform vibration tests in support of the $\mathrm{R}-1$ lateral support system. These tests, coupled with supplemental static tests will determine relative motions between core components, confirm mechanical features of new designs and establish the resistance of components to failure.

f. Using a mockup partial section of the reflector and seal assembly perform thermal gradient tests to aid in determining the strains and deformations which can be expected in the reflector. Verify the properties of the R-l reflector pressings.

g. Perform thermal contact tests to determine thermal resistance of interfaces for material combinations utilized for the core periphery design. Conduct tests to verify the control plate thermal gradient capability.

h. Conduct tests in support of the support plate with plenum and axial support system to evaluate design concepts and obtain mechanical property data.

i. Conduct tests on individual components of the ganged drum drive system and on a 3-drum mockup to develop combined load data for bands and to determine the performance capability of the system under anticipated load and overload conditions when operating in a cyrogenic environment.

j. Perform development tests of shield inserts of the primary shield and shield blocks of the periphery shield, tests of the mounting of the inserts and shield, blocks, and tests of the shield assembly to determine physical and mechanical parameters.

k. Tests will be conducted on individual components of the anti-criticality system to evaluate the effects of withdrawal on fuel element and pedestal assemblies integrity.

1. Limited space environments tests will be performed to provide problem assessment type data.

(2) Maintain cognizance on vibration, acoustic and space effects data available from other space programs so that applicable information can be factored into our test programs.

D. Tooling - Not applicable. 
Subtask 8.0 - Nuclear Subsystem Development

Project 8070 - Corrosion and Flow Development Testing - Technology

A. Engineering

(1) Based upon test requirements, specify where necessary, the flow test program to support the necessary modifications for the XE-2 engine.

(2) Evaluate test results and report findings.

B. Eabrication

(1) Provide for non-fuel test hardware.

(2) Set up and/or assemble test systems and models as required.

C. Testing

(1) Conduct tests in the single element to investigate corrosion in fuel elements.

(2) Conduct tests in the single cluster furnace to evaluate support block corrosion support system and instrumentation (such as exit gas thermocouples) under simulated reactor conditions of load, temperature, and flow conditions. Conduct corrosion tests on single block or block lobes at reduced flow conditions at the exit of a fuel element undergoing hydrogen corrosion tests.

D. Tooling - Not applicable. 
Subtask 8.0 - Nuclear Subsystem Engineering

Project 8071 - Corrosion and Flow Development Testing - Reactor

A. Engineering

(1) Based on the major development categories, the nuclear subsystem component test program in the areas of corrosion, flow and high temperature behavior will be specified incorporating the requirements of the design and analysis functional groups.

(2) An integrated test document will be issued which will describe the test devices and summarizes the tests to be performed in support of the following major development categories.

a. Support Stem Development

b. Cluster Axial Support and Composite Development

c. Fuel Development

d. Core Periphery Development

e. Iateral Support System

f. Reflector and Axial support System

g. Control Drum

h. Core Support Plate and Plena

i. Central Shield and Extension Shield

j. Instrumented Clusters

(3) Test fixtures will be designed and procured for component tests. Wherever possible, modifications of existing test fixtures, and facilities will be made.

(4) Continuous effort will be directed toward improvements of electric heating tests on single elements and clustered configuration directed toward better reactor simulation, higher powers and better electrical contact configurations.

(5) Facility design engineering will continue to be directed toward expanded test cell operations capable of providing electric power heating capability up to 9 megawatts. Hydrogen gas supply facilities commensurate with the power capabilities will be designed.

(6) Test specifications for component pre-qualification tests will be prepared in a coordinated effort with the design and analysis disciplines. 


\section{Project 8071 - (Cont.)}

(7) Support the preparation of the AFSCM 310 Data Items specified in Project 1112 and the NERVA Engine CEI Specification - Part I, as appropriate.

B. Fabrication

(1) Procure, specify, and monitor the fabrication of non-fuel test components and fixtures necessary for corrosion and flow tests.

(2) Set up, modify, or assemble the test systems and models as required for the test program.

(3) Insta]l high-capacity GFE vaporizers.

(4) Procure and install facility modifications.

\section{Testing}

(1) Conduct tests in the single element and single cluster furnaces to assess corrosion in developmental fuel elements. Conduct corrosion tests on single pedestals at prevailing flow conditions downstream of a fuel element undergoing hydrogen corrosion tests. Continue developmental tests to improve simulation of electric tests to reactor operating conditions.

(2) Conduct flow tests for calibration of fuel element orifices, and flow restrictions in the seal and axial support system, and reflector.

(3) Conduct leakage tests on lateral support and seal system.

(4) Conduct tests to measure the permeability and leakage flow characteristics of fuel elements, and graphite interface seals. Conduct permeability tests on fuel elements at elevated temperatures and high pressures.

(5) Conduct flow impedance tests on shield capsules.

(6) Conduct flow impedance and heat transfer tests on the core axial support system.

(7) Conduct tests in the cluster furmace to evaluate combined effects of cluster geometry and corrosion including the center element and pedestal on the element at selected simulated reactor conditions.

(8) Conduct isothermal tests on short thin gaps at varying flow and pressure levels to measure interstitial corrosion and provide corrosion information.

(9) Conduct tests to evaluate design candidates of peripheral configurations at selected simulated reactor conditions. 
Project 8071 (Cont.)

(10) Continue use and operations of liquid to gaseous hydrogen vaporizer with Government-furnished liquid hydrogen.

(1I) Provide temporary shift personnel for required corrosion testing of additional fuel elements.

D. Tooling - Not applicable. 
Subtask 8.0 - Nuclear Subsystem Development

Project 8090 - Reactor Proof Critical Testing - Technology

A. Engineering

(I) Prepare the test plans for XE-2 critical testing.

(2) Update facility operating documents and safety analysis as required by XE-2 critical testing.

(3) Modify experimental apparatus as required by program testing requirements on $\mathrm{XE}-2$.

(4) Provide nuclear experimental assistance to other programs such as NRDS and XE in dosimetry and reactor control, reactor assembly operations, quality control, and fuel fabrication.

(5) Evaluate data and publish results of XE-2 measurements and as needed for EPODing and shimming.

(6) Maintain fuel accountability system for NERVA fuel and SS material at WANEF.

(7) Modify and maintain experimental apparatus and equipment.

(8) Maintain staff operational proficiency through operator training and drills.

(9) Prepare for, and participate in required meetings with AGC, SNPO and IASL.

(10) Modify and maintain reactor and facility systems to meet the requirements of the program.

B. Fabrication

(1) Provide experimental materials in support of the critical testing program.

C. Testing

(1) Conduct experiments on $\mathrm{PAX}$ in support of $\mathrm{XE}-2$; power distributions, reactivity worths and drum span worth measurements, EMND and other instrumentation and test cell environment measurements.

(2) Conduct experiments in PAX and FCX to support analytical methods improvement.

(3) Operate the PAX and FCX reactors as required to accomplish $C$. (I) and C. (2), above. 
Project 8090 (Cont.)

(4) Operate the facility to meet the requirements of the program.

D. Tooling- Not applicable. 
Subtask 8.0 - Nuclear Subsystem Development

Project 8091 - Reactor Proof Critical Testing - Reactor

\section{A. Engineering}

(1) Prepare the test plans for the R-I critical mockup experiments using the PAX assembly. Initiate the test plans for the NCX/R-I in support of the $R-I$ reactor. Prepare test plans for PAX/FCX experiments in support of $\mathrm{R}-1$ shield design and analytical design effort of the $\mathrm{R}-\mathrm{l}$.

(2) Update facility operating documents and safety analysis as required by $\mathrm{FCX}$ and $\mathrm{PAX} / \mathrm{R}-1$ experiments.

(3) Evaluate data and publish results of all measurements.

(4) Provide mechanical and electrical design layouts and detail drawings of reactor and control systems, components, fixtures and handling equipment as requested by WANEF for the PAX assemblies as given in A-I. Initiate mechanical and electrical design layouts and detail drawings of reactor and control systems, components, fixtures and handling equipment as requested by WANEF for NCX/R-I.

(5) Maintain fuel accountability system for NERVA fuel and SS material at WANEF.

(6) Modify and maintain experimental apparatus and equipment.

(7) Maintain staff operational proficiency through operator training and drills.

(8) Prepare for, and participate in required meetings with AGC, SNPO and IASL.

(9) Modify and maintain reactor and facility systems to meet the requirements of the program.

(10) Provide nuclear experimental assistance to other groups at WANL in dosimetry, power calibration, ACPS evaluation, and shipping poison systems.

(11) Support the preparation of the AFSCM 310 Data Items specified in Project 1112 and the NERVA Engine CEI Specification - Part I, as appropriate.

B. Fabrication

(1) Provide experimental materials in support of the critical testing program. 
Project 8091 - (Cont.)

C. Testing

(1) Conduct shielding measurements using the PAX as a source in support of the nuclear subsystem shield design.

(2) Conduct experiments to support the analytical design effort of the nuclear subsystem.

(3) Operate the PAX and FCX reactors as required to accomplish(C-1) and $(C-2)$, above.

(4) Operate the facility to meet the requirements of the program.

D. Tooling - Not applicable. 
Subtask 8.1 - Reactor Procurement

\section{Project 8100 - Reactor Procurement Management - Technology}

\section{A. Engineering}

For the NRX-A6, XE-1, and XE-2 Reactors, developmental test and systems hardware consistent with the planned effort in associated subtasks, provide the following:

(1) Manufacturing guidance to Design Engineering Groups.

(2) Estimate costs and procurement lead times for materials and for fabrication of reactor hardware, development parts, manufacturing tooling, systems hardware, and instrumentation. Determine raw material and manufacturing process requirements in support of procurement and fabrication.

(3) Locate, develop, survey, and provide qualification requirements for prospective suppliers to establish approved-source lists for materials, manufacturing, and services.

(4) Technical assistance to suppliers, and monitor supplier processing to ensure application of proper methods. Conduct a cost and method improvement program.

(5) Review of variation and deviation requests and engineering changes, and determine the effect on reactor component specifications, applications, schedules, and costs.

(6) Review and approve manufacturing and quality control inspection plans, and control the design and manufacture of tooling used to manufacture components.

(7) Provide manufacturing engineering information and support to the procurement of parts made of metallic, graphite, carbide composite, pyrolytic graphite, or other materials.

(8) Manufacturing engineering instructions for packaging for the protection of components and assemblies during handling, shipping, and storage.

(9) Detailed procurement plans and schedules, and the follow of the hardware procurement in accordance with the program plan.

(10) Procurement follow-up for reactor assembly equipment and tooling.

(11) Coordinate and control the delivery of reactor grade components and development parts to end users. Establish and maintain priority scheduling and inventory control on all work in process.

(12) Coordinate and control the delivery of systems hardware from engineering release through delivery to the end user (i.e., Plumbrook, NRDS, Engineering Labs., Sacramento, Waltz Mills, etc.), 
establish and maintain priority scheduling and inventory control on all work in process.

(13) Control the provisioning of the nuclear sub-system Ground support Equipment as follows:

a. Prepare schedules, initiate, and monitor the procurement and delivery of required ground support equipment, checkout equipment, and control system additions to support the NERVA Technology, and facility activation programs.

b. Provide monthly Provisioning Lists, including schedules.

c. Prepare Equipment Status Reports for input to PERT, and for detailed reporting to AGC and SNPO-C.

(14) Provide overall production control of fuel elements at Iarge and $Y-12$. This includes coordination and integration at WNCO and $\mathrm{Y}-12$ production and shipping schedules, integration of corrosion test schedules and expediting of fuel elements at large.

(15) Detail information for PERT schedule reporting.

(16) Provide control of NERVA Material as follows:

a. Provide overall operations of storerooms.

b. Provide for the movement of NERVA Material from Shipping and Receiving to Quality Control and cleaning, as applicable, deliver to the Fluid Flow, Engineering Mechanics and other laboratories, as required, deliver to the WANL Experimental Machine Shop for processing.

c. Provide inventory control based upon project requirements of specially designated reactor and electronic hardware.

d. Clean NERVA hardware in accordance with engineering requirements.

e. Monitor, account for, and dispose of surplus NERVA Material.

(17) Control of the identification, status, condition, location, and application information regarding tooling generated for the manufacture of Reactor Grade Components. Coordinate with Property Control Personnel regarding tool disposition, as required.

(18) Assemble pertinent cost and manpower estimates, and coordinate these with guideline schedules. Provide input data for Program Budgeting for the Reactor Hardware, instrumentation, actuators and controls, and Reactor Procurement Management Projects. Monitor expenditures in subject areas. Report status of Project expenditures against budgets, as required. 
Project $8100-($ Cont.)

(19) Process engineering releases and translate engineering information into procurement/internal production documents. Maintain drawing distribution liaison with AGC/IASL/NRDS, and monitor internal drawing and production document distribution and storage.

(20) Monitor and generate documentation on shipments of NERVA Project Material to NRDS, IASL, AGC, PBRF, and $Y-12$.

(21) Coordinate the release of design, manufacture, and delivery of hardware for the side-by-side shipment and storage of XE-2.

B. Fabrication - Not applicable.

C. Testing - Not applicable.

D. Tooling - Not applicable. 


\section{Subtask 8.1 - Reactor Procurement}

\section{Project 8101 - Reactor Procurement Management - Reactor}

\section{A. Engineering}

For the R-I Reactor developmental test and systems hardware, consistent with the planned effort in associated subtasks, provide the following:

(1) Manufacturing guidance to Deslgn Engineering Groups.

(2) Estimate costs and procurement lead times for materials and for fabrication of reactor hardware, development parts, manufacturing tooling, systems hardware and instrumentation. Determine raw material and manufacturing process requirements in support of procurement and fabrication.

(3) Locate, develop, survey and provide qualification requirements for prospective suppliers to establish approved source lists for materials, manufacturing and services.

(4) Technical assistance to suppliers, and monttor supplier processing to ensure application of proper methods. Conduct a cost and method improvement program.

(5) Review of variation and deviation requests and engineering changes and determine the effect on reactor component specifications, applications, schedules and costs.

(6) Review and approve manufacturing and quality control inspection plans, and control the design and manufacture of tooling used to manufacture components.

(7) Provide manufacturing engineering information and support to the procurement of parts made of metallic, graphite, carbide composite, pyrolytic graphite, or other materials.

(8) Manufacturing Engineering instructions for packaging for the protection of components and assemblies during handling, shipping and storage.

(9) Prepare, develop and monitor Manufacturing Process Development Programs.

(10) Detailed procurement plans and schedules, and the follow of the hardware procurement in accordance with the program plan.

(11) Coordinate and control the delivery of reactor grade components and development parts to end users. Establish and maintain priority scheduling and inventory control on all work in process. 
Project 8I0I - (Cont.)

(12) Detailed planning for the control and delivery of systems hardware from engineering release through delivery to the end user. (i.e. NRDS, Engineering Labs., Sacramento, Waltz Mills, etc.).

(13) Provide overall production control of fuel elements at Large and $Y-12$. This includes coordination and integration of WNCO and $Y-12$ production and shipping schedules, integration of corrosion test schedules and expediting of fuel elements at Large.

(14) Detail information for PERT schedule reporting.

(15) Provide control of NERVA Material as follows:

a. Provide overall operations of storerooms.

b. Provide for the movement of NERVA Material from Shipping and Receiving to Quality Control and cleaning as applicable, deliver to the Fluid Flow, Engineering Mechanics and other laboratories as required; deliver to the WANL Experimental Machine shop for processing.

c. Provide inventory control based upon project requirements of specially designated reactor and electronic hardware.

d. Clean NERVA Hardware in accordance with engineering requirements. e. Monitor, account for and dispose of surplus NERVA Material.

(16) Control of the identification, status, condition, location and application information regarding tooling generated for the manufacture of Reactor Grade Components. Coordinate with Property Control Personnel regarding tool disposition as required.

(17) Assemble pertinent cost and manpower estimates, and coordinate these with guideline schedules. Provide input data for Program Budgeting for the Reactor Hardware, instrumentation, actuators and controls, and Reactor Procurement Management Projects. Monitor expenditures in subject areas. Report status of Project expenditures against budgets as required.

(18) Process engineering releases and translate engineering information into procurement/internal production documents. Maintain drawing distribution liaison with AGC/IASI/NRDS and monitor internal drawing and production document distribution and storage.

(19) Monitor and generate documentation on shipments of NERVA Project Materials to NRDS, IASL, AGC. PBRF, and Y-12.

(20) Support the preparation of the AFSCM 310 Data Items specified in Project 1172 and the NERVA Engine CEI Specification - Part I, as appropriate. 
Project $8101-$ (Cont.)

B. Fabrication - Not applicable.

C. Testing - Not applicable.

D. Tooling - Not applicable. 
Subtask 8.1 - Reactor Procurement

\section{Project 8106 - Reactor Procurement Management - PEWEE}

\section{A. Engineering}

For the PEWEE Reactors and developmental test hardware, consistent with the currently planned effort in associated subtasks, provide the following:

(1) Manufacturing guidance to Design Engineering Groups.

(2) Estimate costs and procurement lead times for materials and for fabrication of reactor hardware, development parts, and manufacturing tooling. Determine raw material and manufacturing process requirements in support of procurement and fabrication.

(3) Locate, develop, survey and provide qualification requirements for prospective suppliers to establish approved source lists for materials, manufacturing and services.

(4) Technical assistance to suppliers, and monitor supplier processing to ensure application of proper methods. Conduct a cost and method improvement program.

(5) Review of variation and deviation requests and engineering changes and determine the effect on reactor component specifications, applications, schedules and costs.

(6) Review and approve manufacturing and quality control inspection plans, and control the design and manufacture of tooling used to manufacture components.

(7) Provide manufacturing engineering information and support to the procurement of parts made of graphite, carbide composite, pyrolytic graphite, or other materials.

(8) Manufacturing engineering instructions for packaging for the protection of components and assemblies during handling, shipping and storage.

(9) Detailed procurement plans and schedules, and the follow of the hardware procurement in accordance with the program plan.

(10) Coordinate and control the delivery of reactor grade components and development parts to end users. Establish and maintain priority scheduling and inventory control on all work in process.

(II) Provide overall production control of fuel elements at Large and Y-12. This includes coordination and integration of WNCO and $\mathrm{Y}-12$ production and shipping schedules, integration of corrosion test schedules and expediting of fuel elements at Large. 
Project 8106 (Cont.)

(12) Detail information for PERT schedule reporting.

(13) Provide control of subject Material as follows:

a. Provide overall operation of storerooms.

b. Provide for the movement of subject Material from Shipping and Receiving to Quality Control as applicable, dellver to the WANL Experimental Machine Shop for processing.

c. Monitor, account for and dispose of surplus Material.

(14) Control of the identification, status, condition, location and application information regarding tooling generated for the manufacture of Reactor Grade Components. Coordinate with Property Control Personnel regarding tool disposition as required.

(15) Assemble pertinent cost and manpower estimates, and coordinate these with guideline schedules. Provide input data for Program Budgeting for the Reactor Hardware, and Reactor Procurement Management Projects. Monitor expenditures in subject areas. Report status of Project expenditures against budgets as required.

(16) Process engineering releases and translate engineering information into procurement/internal production documents. Maintain drawing distribution liaison with AGC/IASL/NRDS and monitor internal drawing and production document distribution and storage.

(17) Monitor and generate documentation on shipments of NERVA Project Material to NRDS, IASL, and Y-I2.

B. Fabrication - Not applicable.

C. Testing - Not applicable.

D. Tooling - Not applicable. 
Subtask 8.1 - Reactor Procurement

Project 8110 - Reactor Hardware Fabrication - Technology

A. Engineering - Not applicable.

B. Fabrication

(1) Provide all hardware other than fuel and the components supplied by Project 8140 , for the NRX-A6, XE-1, XE-2 Reactors and NRX $-A$.7 termination, in compliance with established procurement plans and schedules.

(2) Provide side-by-side fuel element test hardware for use during shipment and storage of $\mathrm{XE}-2$ as follows:

a. Four clusters which are duplicates of XE-2 clusters but may be less than reactor grade.

b. Four containment vessels for the clusters.

c. Attachment hardware to anchor the containment vessels to the pressure vessel.

d. Plumbing required to circulate the purge gas from the inlet side of the reactor purge system, through the containment vessels, and out the exit side of the reactor purge system.

C. Testing - Not applicable.

D. Tooling - Not applicable. 
Subtask 8.1 - Reactor Procurement

Project 8111 - Reactor Hardware Fabrication - Reactor

A. Engineering - Not applicable.

B. Fabrication

Provide for the replacement of NR-l beryllium powder used for pressing NRX-A7 rings.

C. Testing - Not applicable.

D. Tooling - Not applicable. 
Subtask 8.1 - Reactor Procurement

\section{Project 8116 - Reactor Hardware Fabrication - PEWEE}

A. Engineering - Not applicable.

B. Fabrication

Provide all hardware other than fuel and the components supplied by Project 8146 for the Pewee Reactors, in compliance with established procurement plans and schedules. Pewee II requirements are planned for two-thirds of the total number of fuel elements and the same quantity of cluster components as Pewee I.

C. Testing - Not applicable.

D. Tooling - Not applicable. 
Subtask 8.1 - Reactor Procurement

Project 8120 - Reactor Instrumentation - Technology

A. Engineering - Not applicable.

B. Fabrication

Provide instrumentation hardware for NRX-A6, XE-1, and XE-2 in compliance with established procurement plans and schedules.

C. Testing - Not applicable.

D. Tooling - Not applicable. 
Subtask 8.1 - Reactor Procurement

Project 8130 - Reactor Controls - Technology

A. Engineering - Not applicable.

B. Fabrication

(1) Provide reactor control hardware for $\mathrm{NRX}-\mathrm{A} 6, \mathrm{XE}-1$ and $\mathrm{XE}-2$ in compliance with established procurement plans and schedules.

(2) Modify and repair the following existing XE controllers:

a. Print-out switching unit.

b. Two 10-channel Averagers.

C. Testing - Not applicable.

D. Tooling - Not applicable. 
Subtask 8.1 - Reactor Procurement

Project 8140 - Reactor Graphite Component Fabrication - Technology

A. Engineering

(1) Qualify materials and processes for the fabrication of XE-2 reactor graphite components. Provide processing details for shop fabrication. Provide shop surveillance and assist in resolution of any technical problems. Coordinate with WANL Materials and Reactor Engineering personnel the disposition of deviated products, and also the review and approval of all Product Specifications and Drawings prior to start of core fabrication.

(2) Provide technical reports on accomplishments.

B. Fabrication

(1) Complete the processing of ordered quantities of coated graphite support blocks, filler strips, cups and washers, for the $\mathrm{XE}-2$ reactor.

(2) Procure to specification the raw materials required for processing coated graphite support blocks, cups and washers for the XE-2 reactor.

C. Testing - Not applicable.

D. Tooling

(1) Procure all necessary tooling for fabrication operations to meet the schedules for coated graphite components for the $\mathrm{XE}-2$ reactor. 
Subtask 8.1 - Reactor Procurement

Project 8146 - Reactor Graphite Component Fabrication - PEWEE

A. Engineering

(1) Develop materials and processes for fabrication of PEWEE reactor graphite components. Provide processing details for shop fabrication. Provide shop surveillance and assist in the resolution of any technical problems. Coordinate with WANL materials and reactor engineering personnel the disposition of deviated products, and also the review and approval of all Product Specifications and Drawings prior to start of core fabrication.

(2) Provide technical reports on accomplishments.

B. Fabrication

(1) Complete the processing of ordered quantities of coated graphite and composite components for the PEWEE reactors.

(2) Procure to specification raw materials required for processing coated graphite and composite components for the PEWEE reactors.

C. Testing - Not applicable.

D. Tooling

(1) Procure all necessary tooling for fabrication operations to meet the requirements for coated graphite components for the PEWEE reactors. 
Subtask 8.1 - Reactor Procurement

Project 8150 - Reactor Graphite Component Quality Control - Technology

\section{A. Engineering}

Conduct a Quality Control Program in accordance with WANL Work Orders, Drawings, Specifications, and Procurement Quality Requirements for the fabrication of Reactor Graphite components required for the XE-2 reactor and component development in compliance with established procurement plans and schedules. This progtram shall be in compliance with the requirements of WANL-TNR-088, Revision F, NERVA Subsystem Product Assurance Program Plan.

(1) Update, coordinate, and distribute a process and inspection plan for the $\mathrm{XE}-2$ reactor.

(2) Prepare, maintain, and distribute records which will provide positive evidence that the inspection of each characteristic required by drawings and specifications has been performed.

(3) Support the PDP5 data processing equipment located at the wNCO Facility as it relates to the project.

(4) Provide vendor surveillance on Code 1 deliverable hardware raw materials to the extent required by specification. Provide vendor surveillance on Code 2 and Code 3 non-deliverable hardware which can directly affect the characteristic of deliverable hardware to the extent determined by Quality Control and Process Engineering, based on drawing, specification, and product considerations. Provide receiving inspection and laboratory analysis and tests on Code 1, Code 2, or Code 3 raw materials and hardware as required.

(5) Monitor conformance of the manufacturing operations in accordance with established processes and procedures; document deviations from the procedures; recommend corrective action.

(6) Provide for other NERVA projects the inspection of the coated reactor graphite components that are fabricated for use in special component tests. The number of inspection operations for these components will be adjusted to provide that information on characteristics which is required by the cognizant NERVA projects.

B. Fabrication - Not applicable.

C. Testing - Not applicable.

D. Tooling - Not applicable. 
Subtask 8.1 - Reactor Procurement

Project 8156 - Reactor Graphite Component Quality Control - PEWEE

A. Engineering

Conduct a Quality Control Program in accordance with WANL Work Orders, Specifications, Drawings, and Procurement Quality Requirements for the fabrication of Reactor Graphite components required for the PEWEE I and PEWEE 2 reactors and component development in compliance with established procurement plans and schedules. This program shall be in compliance with the requirements of WANL-TNR-088, Revision F, NERVA Subsystem Product Assurance Program Plan.

(1) Update, coordinate, and distribute a process and inspection plan for the PEWEE reactors.

(2) Prepare, maintain, and distribute records which will provide positive evidence that the inspection of each characteristic required by drawings and specifications has been performed.

(3) Support the PDP5 data processing equipment located at the WNCO Facility as it relates to this project.

(4) Provide vendor surveillance on Code 1 deliverable hardware raw materials to the extent required by specification. Provide vendor surveillance on Code 2 and Code 3 non-deliverable hardware which can directly affect the characteristic of deliverable hardware to the extent determined by Quality Control and Process Engineering, based on drawing, specification, and product considerations. Provide receiving inspection and laboratory analysis and tests on Code 1 , Code 2 , or Code 3 raw materials and hardware as required.

(5) Monitor conformance of the manufacturing operations in accordance with established processes and procedures; document deviations from the procedures; recommend corrective action.

(6) Provide for other NERVA projects the special inspection data of the Reactor Graphite components that are fabricated for use in the PEWEE I and PEWEE 2 reactors. The number of inspection operations for these components will be adjusted to provide that information which is required by the cognizant NERVA projects.

B. Fabrication - Not applicable.

C. Testing - Not applicable.

D. Tooling - Not applicable. 
Subtask 8.1 - Reactor Procurement

Project 8160 - Reactor Fuel Element Quality Control - Technology

A. Engineering

Conduct a Quelity Control Program in accordance with WANL Work Orders, Specifications, Drawings and Procurement Quality Requirements, for the fabrication of reactor fuel elements and special non-fueled elements for the XE-2 reactor in compliance with established plans and schedules. This program shall be in compliance with the requirements of WANL-TNR088, Revision F, NERVA Subsystem Product Assurance Program Plan.

(1) Update, coordinate, and distribute a process and inspection plan for the XE-2 reactor configuration.

(2) Prepare, maintain, and distribute records which will provide positive evidence that the inspection of each characteristic required by drawings and specification had been performed.

(3) Support the PDP5 data processing equipment located at the WNCO Facility as it relates to this project.

(4) Provide vendor surveillance on Code 1 deliverable hardware raw materials to the extent required by specification. Provide vendor surveillance on Code 2 and Code 3 non-deliverable hardware which can directly affect the characteristics of deliverable hardware to the extent determined by Quality Control and process Engineering, based on drawing, specification, and product considerations. Provide receiving inspection and laboratory analysis and test on Code 1 , Code 2, and Code 3 raw materials and hardware as required.

(5) Provide for other NERVA projects the special inspection data of reactor fuel elements and special non-fueled elements that are fabricated for use in the XE-2 reactor. The number of inspection operations for these components will be adjusted to provide that information which is required by the cognizant NERVA project.

(6) Monitor conformance of the WNCO manufacturing operations in accordance with established processes and procedures; document deviations from the procedures; recommend corrective action.

B. Fabrication - Not applicable.

C. Testing - Not applicable.

D. Tooling - Not applicable. 
Subtask 8.1 - Reactor Procurement

Project 8166 - Reactor Fuel Element Quality Control - PEWEE

A. Engineering

Conduct a Quality Control Program in accordance with WANL work orders, specifications, drawings and Procurement quality Requirements for the fabrication of reactor fuel elements for the PEWEE reactors in compliance with established plans and schedules. This program shall be in compliance with the requirements of WANL-TNR-088, Revision F, NERVA Subsystem Product Assurance Program Plan.

(1) Update, coordinate and distribute a process and inspection plan for the PEWEE configuration.

(2) Prepare, maintain and distribute records which will provide positive evidence that the inspection of each characteristic required by drawings and specifications has been performed.

(3) Support the PDP5 data processing equipment located at the WTNCO Facility as it relates to this project.

(4) Provide vendor surveillance on Code I deliverable hardware raw materials to the extent required by specification. Provide vendor surveillance on Code 2 and code 3 non-deliverable hardware which can directly affect the characteristics of deliverable hardware to the extent determined by Quality Control and Process Engineering, based on drawings, specifications and product considerations. Provide receiving inspection and laboratory analysis and tests on Code 1, Code 2 or code 3 raw materials and hardware as required.

(5) Provide for other NERVA projects the special inspection data of the fuel elements that are fabricated for use in the PEWEE reactors. The number of inspection operations for these components will be adjusted to provide that information which is required by the cognizant INERVA projects.

(6) Monitor conformance of the WTCO manufacturing operations in accordance with established processes and procedures; document deviations from the procedures; recommend corrective action.

B. Fabrication - Not applicable.

C. Testing - Not applicable.

D. Tooling - Not applicable. 
Subtask 8.1 - Reactor Procurement

Project 8170 - Quality Control - Corrosion Tests - Technology
A. Engineering - Not applicable.
B. Fabrication - Not applicable.
C. Testing

(1) Perform corrosion testing of fuel elements and support blocks representative of production units to test their corrosion resistance and to insure their conformance to applicable approved specifications. The testing will be performed on fuel elements and support blocks representative of production unit for the XE-2. Testing will be accomplished at the present rate of one (1) successful test per coating batch for both WNCO and Y-12 production.

D. Tooling - Not applicable. 
Subtask 8.1 - Reactor Procurement

Project 8176 - Quality Control - Corrosion Tests - PEWEE

A. Engineering - Not applicable.

B. Fabrication - Not applicable.

C. Testing

(1) To prepare the facility for the applicable qualification tests of fuel for the PEWEE reactors. Perform corrosion testing of fuel elements representative of production units to test their corrosion resistance and to insure their conformance to applicable approved specifications. The testing will be performed on fuel elements representative of production quality. Testing will be accomplished at the present rate of one (1) successful test per coating batch.

D. Tooling - Not applicable. 
Subtask 8.1 - Reactor Procurement

Project 8180 - Reactor Fuel Element Fabrication - Technology

A. Engineering - Not applicable.

B. Fabrication

(1) Complete the fabrication of the work order quantities of reactor fuel elements and special non-fueled elements for the XE-2 reactor, including all additional elements needed for product evaluation and certification.

(2) Complete the procurement of the raw materials required for the XE-2 reactor fuel elements and special non-fueled elements in compliance with established plans, specifications and schedules.

(3) Provide fuel material for GFE fabrication of the XE-2 reactor fuel elements.

(4) Support the PDP-5 data processing equipment located at the WNCO Facility.

C. Testing - Not applicable.

D. Tooling

(1) Procure all necessary tooling for fabrication operations to meet the XE-2 reactor fuel elements and special non-fuel element requirements. 
Subtask 8.1 - Reactor Procurement

Project 8186 - Reactor Fuel Element Fabrication - PEWEE

A. Engineering - Not applicable.

B. Fabrication

(1) Complete the fabrication of the work order quantities of fuel elements for the PEWEE reactors, including all additional elements needed for product evaluation and certification.

(2) Complete the procurement of the raw materials required for the PEWEE reactor fuel elements in compliance with established plans, specifications and schedules.

(3) Provide fuel material for GFE fabrication of the PEWEE reactors fuel elements.

(4) Support the PDP-5 data processing equipment located at the WNCO Facility.

(5) Implement new processes and methods to increase process yields and improve product quality.

C. Testing - Not applicable.

D. Tooling

(1) Procure all necessary tooling for fabrication operations to meet the PEWEE reactor fuel element requirements. 
Subtask 8.1 - Reactor Procurement

Project 8190 - Reactor Assembly and Shipping - Technology

A. Engineering

(1) Maintain the capability of assembling or disassembling $\mathrm{NRX}$ and $\mathrm{XE}$ reactors through shipment of $\mathrm{XE}-2$.

(2) Create and maintain current Assembly Process Outlines designating the sequential operations to be utilized in every operation of instrumentation application, assembly, disassembly, packaging and shipping performed by the Assembly Department.

(3) Design, procure and/or modify, qualify, and/or install tooling, fixtures and other specialty hardware, materials, and services for NRX and XE reactors.

(4) Investigate and resolve technical problems encountered in performing operational functions in the Assembly Department.

(5) Evaluate all reactor hardware design changes to determine any impact on assembly procedures, tooling, fixtures, and schedules and take appropriate action to accommodate the changes with the minimum effect on schedule requirements.

(6) Prepare and administer shipping plans and procedures for $X E$ reactor shipments to and from test sites.

(7) Determine the disposition of $\mathrm{NRX} / \mathrm{XE}$ tooling and equipment that will not be required for the NERVA program.

(8) Create, implement, and administer procedures and policies relative to nuclear and radioisotope safety for assembly and shipping reactors or components.

(9) Monitor design, initiate procurement of the equipment and perform modifications to existing instrumentation railroad car as required to record shock/vibration during reactor shipment.

B. Fabrication

(1) Plan and establish schedules for requirements of detailed parts and detailed work efforts to meet scheduled delivery dates for $X E$ reactors. 
Project 8190 (Cont.)

(2) Prepare and control parts for assembly by cleaning, packaging and/or grouping into preassembly kits.

(3) Perform instmumentation subassemblies, termination lead preparation.

(4) Assemble $\mathrm{XE}-2$ pedestals and engine mounted nuclear detectors.

(5) Complete the assembly of XE-2.

(6) Prepare for shipment and transport XE-2 to NRDS.

(7) Assemble mechanical mockup subassemblies and assemblies as required for developing or checking assembly processes and for tooling and equipment tryouts.

(8) Conduct training programs to instruct personnel in performing new or modified processes.

(9) Modify existing reactor shipping and transport equipment and/or procure new equipment as necessary to accomplish the work within the scope of this project.

(10) Build XE-1 Experimental Controllers - Chassis II.

(II) Dismantle and prepare $\mathrm{NRX}-\mathrm{XE}$ tooling and equipment for release to Property Administration.

(12) Assemble and/or disassemble and reassemble reactor components or subassemblies for Flexible Critical Experiments (FCX).

C. Testing

(1) Conduct development and qualification tests of equipment and assembly personnel relative to instrumentation processes such as brazing, welding application and potting, and other specialized assembly processes.

(2) Perform load tests as required on lifting and handing equipment.

D. Tooling - As required. 
Project 8.1 - Reactor Procurement

Project 8191 - Reactor Assembly and Shipping - Reactor

A. Engineering

(1) Develop concept of tooling and capability of assembling critical experiments, various NERVA equipment and provide preliminary studies for the assembIy of NERVA reactors.

(2) Create and administer procedures and policies relative to nuclear and radioisotope safety for assembling and shipping all reactors or components.

(3) Initiate criticality studies of fuel storage and fuel handling equipment to support the NERVA Reactor Assembly.

(4) Establish liaison with design, in the early stages of design, in order to provide input relative to assembly techniques, and thereby establish the preliminary concepts for assembly operations and tooling.

(5) Develop and formulate plans for any development work to be performed for assembly and fabrication processes.

(6) Initiate preliminary assembly process outlines designating the sequential operations to be utilized in operations of instrumentation application and assembly.

(7) Monitor the design and development concepts of a simulated reactor and all supporting equipment for a simulated reactor/pressure vessel shipment.

B. Fabrication

(1) Plan and establish preliminary schedules for requirements of longlead items such as complex tooling, equipment, atc.

C. Testing - Not applicable.

D. Tooling - Not applicable. 
Subtask 8.9 - General Support for Reactor Development

Project 8901 - Fuel Element Process Development and Control - NERVA Reactor

A. Engineering

(1) Evaluate and incorporate materials and processing information supplied by WANL Materials and Fuel Development to WNCO during the XE-2, Process Improvement, and PEWEE Programs.

(2) Develop, evaluate, and incorporate, if applicable, improved processes or procedures for increased yield, improved quality or reduced cost.

(3) Provide detailed process specifications and technical assistance for the fabrication of fuel elements and special non-fuel elements.

(4) Procure raw material, to the applicable specification, for the production of fuel elements during the Process Improvement Program.

(5) Monitor performance of production fuel element fabrication; assist in resolving technical problems; and coordinate with WANL Materials and Reactor Engineering the final approval of Product Specification and Drawings.

(6) Prepare technical reports on development and fabrication a.complishments at WNCO.

(7) Provide equipment, fixture and tool engineering required in the development, qualification, and production of those elements involved in the Process Improvement Program.

(8) Support the PDP-5 data processing equipment located at the WNCO Facility.

(9) Support the engineering effort required to improve equipment for the production of WNCO products.

(10) Procure advanced performance fuel bead particles from a commercial supplier and perform the required analytics.

B. Fabrication

(1) Conduct a program directed at incorporating proven procedures for increased yield, improved quality and cost reduction into fabrication processes. This program will also be used to debug new processes, checkout new equipment, and assure that all specification requirements can be met. Produce quantities of fuel elements in compliance with approved plans and schedules. 
Project 8901 (Cont.)

(2) Complete required equipment qualification or new process verification runs during this program.

(3) Fabricate or purchase replacement or maintenance parts and supplies for Government furnished equipment.

(4) Increase the capacity of the recoverable scrap storage facility by approximately 124 drums and birdcages.

C. Testing

(1) Conduct performance tests necessary to demonstrate the adequacy of repaired and installed on-line equipment.

D. Tooling

(1) Procure necessary tooling for process development and production during the $\mathrm{XE}-2$, Process Improvement and Pewee Programs. 
Subtask 8.9 - General Support for Reactor Development

Project 8921 - Fuel Element Materials Development - Reactor

\section{A. Engineering}

(1) Design and carry out development studies to improve element properties, lifetime, reliability, and processes for application in reactors.

(2) Provide preliminary evaluation of selected novel materials and/or processes for advanced fuel elements.

(3) Provide test specifications for fuel-associated test programs under this project as required.

(4) Coordinate fuel development activities with those of WNCO, UCNC:Y-12, and LASL, and other SNPO-supported activities.

(5) Provide assistance in establishment of quality control procedures under Subtask 2.6, Project 8161 and corrosion testing criteria based upon results from applicable studies.

(6) Evaluate results of hydrogen corrosion testing of developmental fueled elements, raw materials and process variables, and evaluate fabrication process parameters.

(7) Provide guidance and support for all reactor post-operation programs. Define necessary fuel development programs based upon post-mortem analysis.

(8) Provide supervision of schedular and testing control on production and developmental fuel, including $\mathrm{CF} E$ sources, and regulate the interaction of such fuel with the XE-2 and PEWE' schedules.

(9) Obtain resolution of VR and AR actions evolving from fuel programs, and apply corrective measures for problems delaying fuel procurement.

(10) Perform studies in the following areas as required:

a. Bead development and evaluations

b. Organometallics for $\mathrm{NbC}$ coating

c. " $\mathrm{X}$ " coat development

d. Thermal processing development 


\section{Project 8921 (Cont.)}

(11) Initiate and expedite studies on the effect of increased uranium loading on physical and thermal properties of fuel elements, on coating behavior, and in corrosion test performance.

(12) Initiate studies on extmusion die and process development to achieve uniform density, thermal properties, electrical properties, coating behavior, and test performance.

(13) Provide topical reports in relevant areas.

(14) Support the preparation of the AFSCM 310 Data Items specified in Project 1112 and the NERVA Engine CEI Specification - Part 1, as appropriate.

B. Fabrication

(1) Provide fabrication and test facilities, equipment, and staff to accomplish project objectives.

(2) Fabricate reference and advance experimental fueled and unfueled elements and/or related specimen materials.

C. Testing

(1) Conduct chemical analyses, mechanical, and thermophysical property measurements, metallography, and any other similar testing as required to support fuels, and raw materials, development activities.

D. Tooling

(1) Procure necessary equipment, instrumentation, fixtures, and special tooling in support of development efforts related to fuel elements, raw materials, and reactor structural components. 
Subtask 8.9 - General Support for Reactor Development

Project 8931 - Graphite and Composite Structural Materials Development - Reactor

A. Engineering

(1) Review and revise specifications for carbide-graphite composite structural materials in coordination with related efforts under Project 2809 and in compliance with current performance, design and process requirements.

(2) Review and revise specifications for structural grades of graphite for specific reactor applications such as seal segments, filler strips, etc., in coordination with Project 2809.

(3) Provide assistance in establishment of quality control procedures and corrosion testing criteria based on results from applicable studies.

(4) Evaluate results of hydrogen corrosion testing of referenced coated graphites and composites.

(5) Continue consultation with the various Nuclear Subsystem Engineering groups in Subtask 8.0 with regard to materials data input and interpretation of component tests.

(6) Continue assistance in the evaluation of irradiated graphite and composite materials from reactor power hot tests (post-mortem) including corrosion and irradiation effects. Define necessary developmental programs based on post-mortem analysis.

B. Fabrication

(1) Fabricate development quantities of carbide-graphite composites in support of structural material development programs.

C. Testing

(1) Conduct chemical analyses, mechanical and thermophysical property measurements, metallography, and any other similar testing as required to support structural graphite, composites, and carbide development activities.

(2) Qualify commercial vendors for production of graphite and composite materials for application to $R$ reactor designs and requirements.

D. Tooling - As required. 


\section{Project 8959 - Physics and Mathematics - Support}

\section{A. Engineering}

(1) Basic cross-section evaluation of microscopic data taking into account integral reactor measurements will be conducted. Improved method for obtaining spectrum averaged cross-section, improved crystalline models and scattering analysis in the thermal range will be incorporated into the cross-section analysis.

(2) The results of Flexible Critical Tests will be analyzed to determine the validity of cross-section evaluations and neutron transport methods. The Physics and Mathematics Group will contribute to the design of flexible critical experiments and provide support with basic nuclear data.

(3) Prepare and submit reactor and shield codes to NASA and Argonne Code Centers.

(4) Computer programing effort will be expended to produce a modular system of digital computer programs. The word modular implies the following characteristics:

a. Each program will be self-contained and able to solve a particular problem if given the correct input.

b. The data produced by any program will be readily available to other programs.

c. Each program can be easily replaced by another program which serves the same function.

d. All programs, provided only that they are written in an acceptable language, must fit into the system with a minimum amount of modifications.

(5) Intensify development of full $\mathrm{P}_{2}$ and $\mathrm{P}_{3}$ scattering matrix capability in both the fast and ${ }^{2}$ thermal energy ranges based on the recently completed WANL program GAMBIT. This includes evaluation and input of data from ENDF and other sources.

(6) Develop methods for accounting for photon production by resonance capture and inelastic scattering.

B. Fabrication - Not applicable.

C. Testing - Not applicable.

D. Tooling - Not applicable. 